\title{
Unintended Social and Economic Consequences Resulting from the Implementation of New Construction Technologies in the Developing World
}

Andrew J. South

Brigham Young University - Provo

Follow this and additional works at: https://scholarsarchive.byu.edu/etd

Part of the Construction Engineering and Management Commons, and the Economics Commons

\section{BYU ScholarsArchive Citation}

South, Andrew J., "Unintended Social and Economic Consequences Resulting from the Implementation of New Construction Technologies in the Developing World" (2011). Theses and Dissertations. 2807.

https://scholarsarchive. byu.edu/etd/2807

This Thesis is brought to you for free and open access by BYU ScholarsArchive. It has been accepted for inclusion in Theses and Dissertations by an authorized administrator of BYU ScholarsArchive. For more information, please contact scholarsarchive@byu.edu, ellen_amatangelo@byu.edu. 
Unintended Social and Economic Consequences Resulting from the Implementation of New Construction Technologies in the Developing World

Andrew J. South

A thesis submitted to the faculty of

Brigham Young University

in partial fulfillment of the requirements for the degree of

Master of Science

Mark Hutchings, Chairman

Jay Chirstofferson

Jay Newitt

School of Technology

Brigham Young University

August 2011

Copyright ( 2011 Andrew South

All Rights Reserved 


\begin{abstract}
Unintended Social and Economic Consequences Resulting from the Implementation of New Construction Technologies in the Developing World
\end{abstract}

\author{
Andrew South \\ School of Technology \\ Master of Science
}

One of the key components of international development is to provide adequate shelter for citizens of developing countries. This is often accomplished by governmental, nongovernmental, and private organizations that seek to lower the cost, increase the quality, and expand the availability of safe, sustainable housing through the use of innovative technologies. These new technologies can affect the social and/or economic structure within communities. This paper is a case study resulting from the construction of a seventy-one-home village, including infrastructure, near Yogyakarta, Indonesia by a foreign, aid-based non-governmental organization (NGO). The village was relocated less than two kilometers from its original site after a massive landslide, triggered by the 2006 earthquakes of Central Java, virtually destroyed the entire community. Four years after construction the researcher took an inductive inquiry approach through interviews with residents of the community and residents of neighboring communities to understand the social and economic impacts. The research project explored the unintended consequences to the community resulting from the NGO's use of innovative housing technologies (steel reinforced concrete domes and planned community development) without a thorough understanding of underlying community culture and interactions.

Keywords: Andrew South, unintended consequences, international development, built environment, technology transfer, sustainability, concrete domes, planned communities 


\section{ACKNOWLEDGEMENTS}

Many individuals supported this research project, and I express my gratitude for their contributions. Specifically, the graduate committee and department faculty for their insights and guidance, my parents and brothers/business partners who have encouraged my educational

pursuits, and my wife and children who were patient and understanding with the time it took to complete the research. 


\section{TABLE OF CONTENTS}

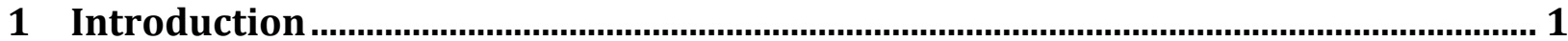

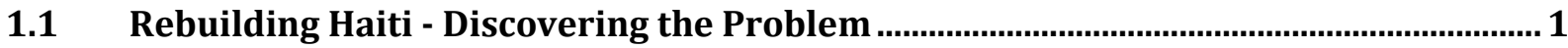

1.2 Statement of the Problem

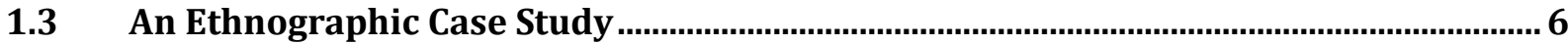

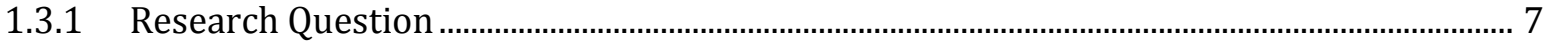

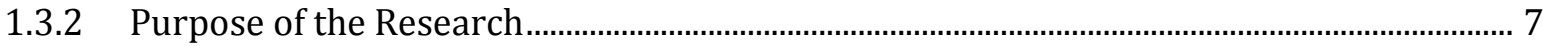

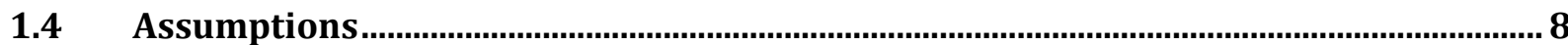

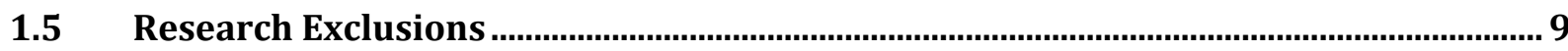

1.6 Personal Affiliation Disclosure

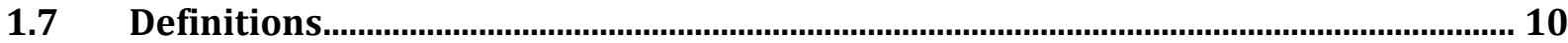

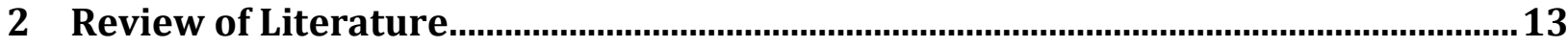

2.1 Construction and International Development......................................................... 13

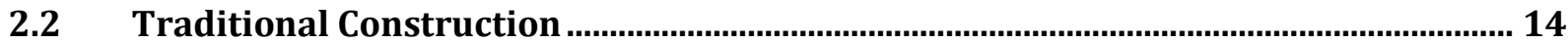

2.3 Contracting and Self-Help 16

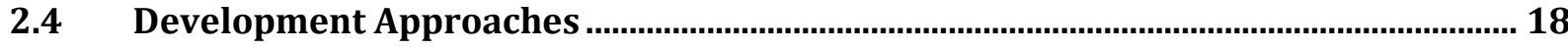

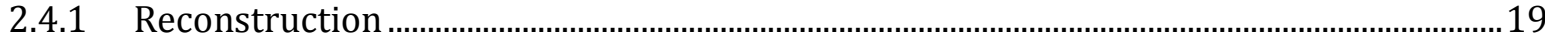

2.4.2 Community-Based Development.........................................................................................

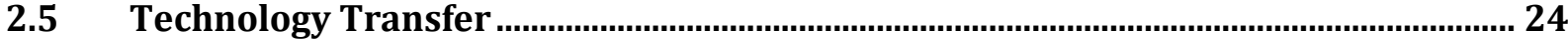

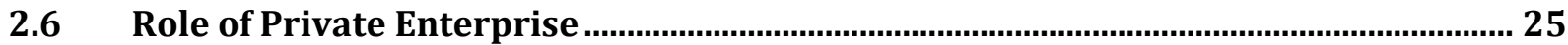

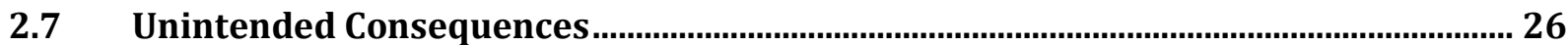

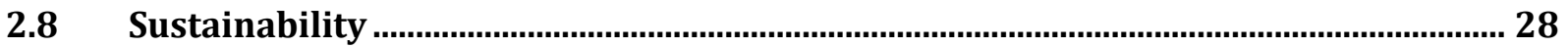

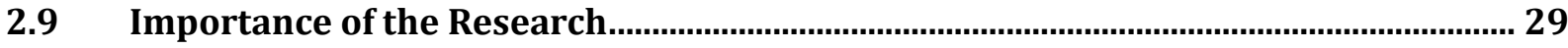

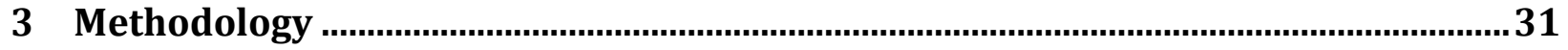




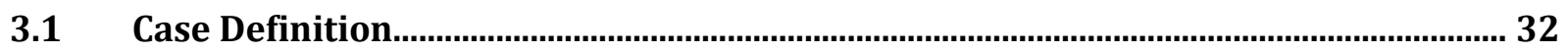

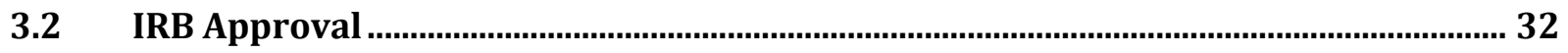

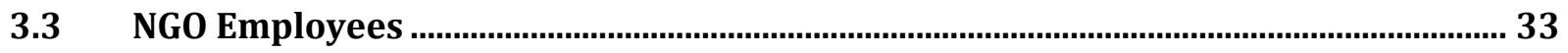

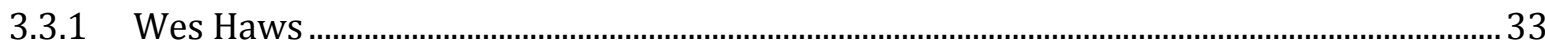

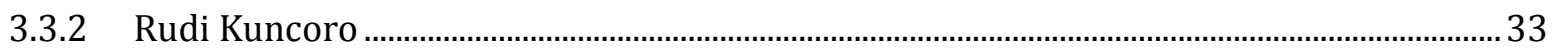

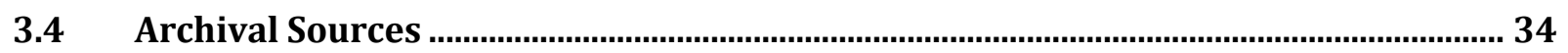

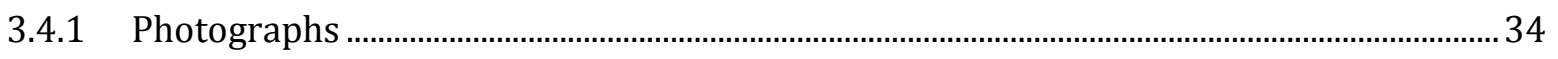

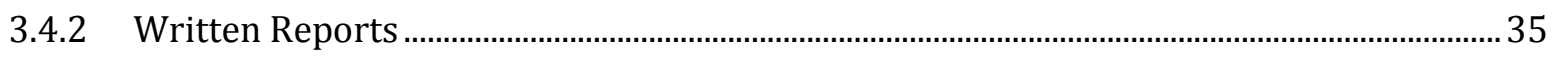

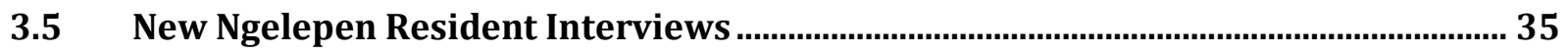

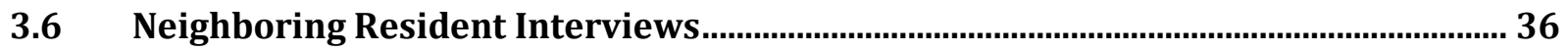

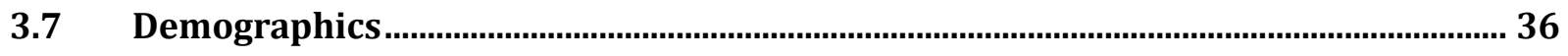

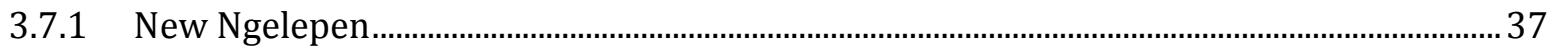

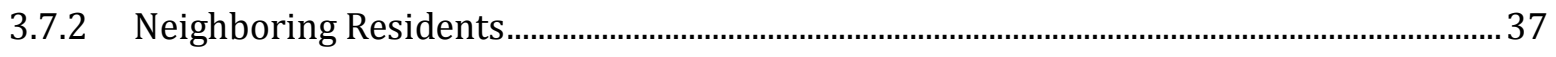

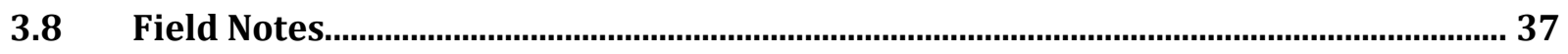

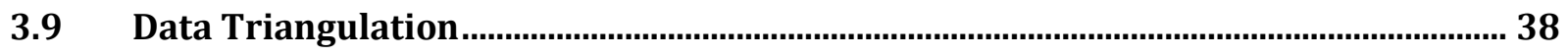

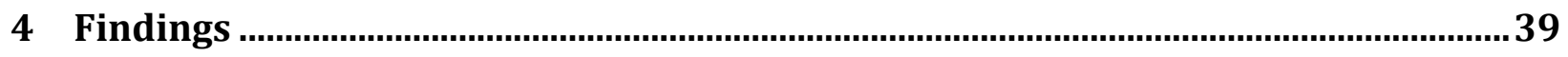

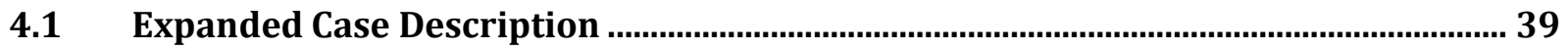

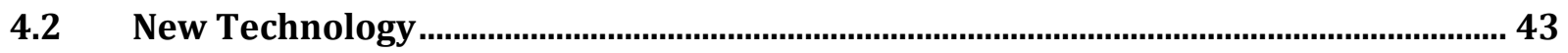

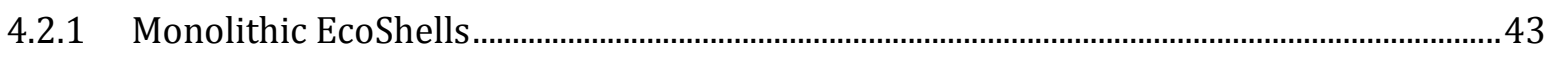

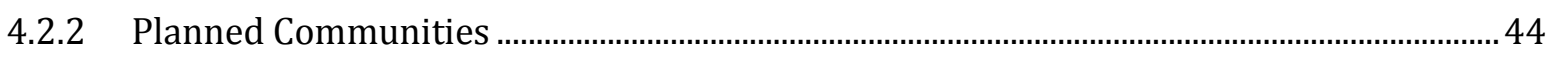

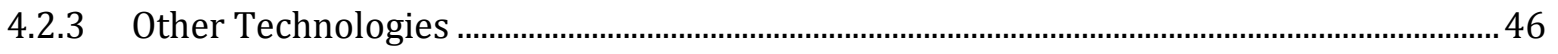

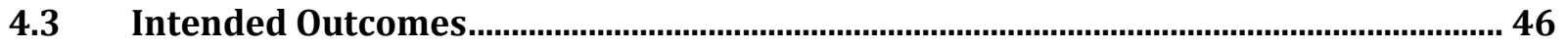

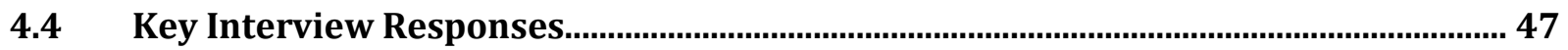

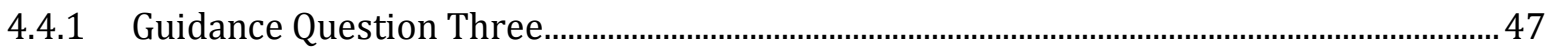

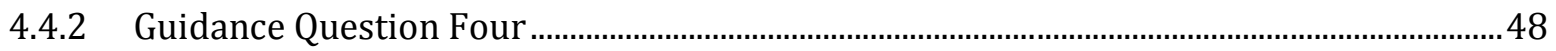




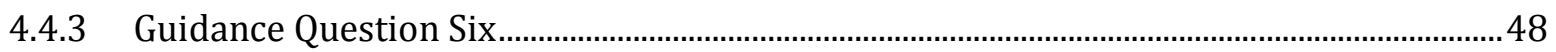

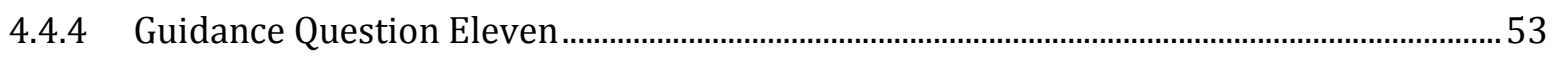

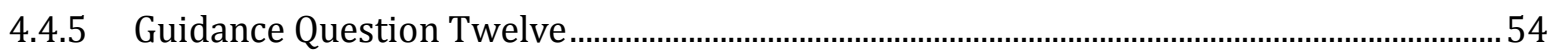

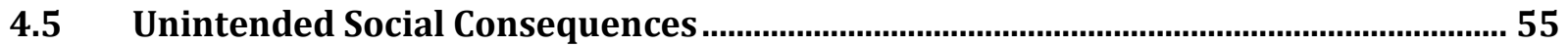

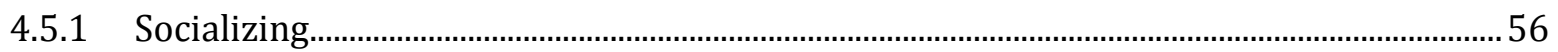

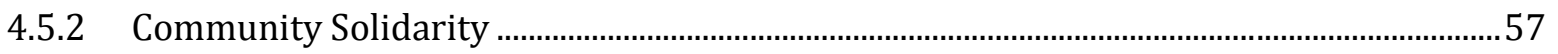

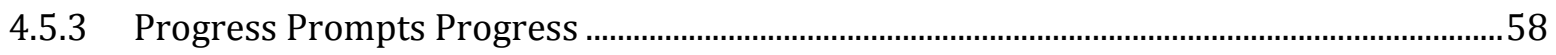

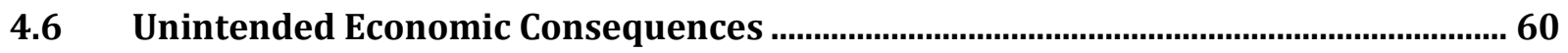

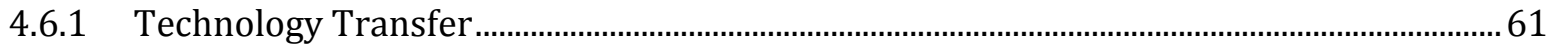

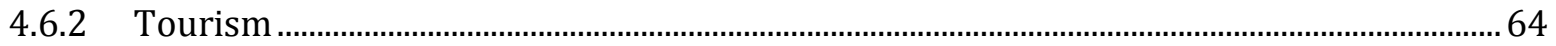

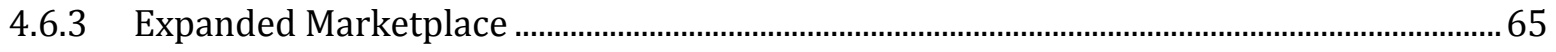

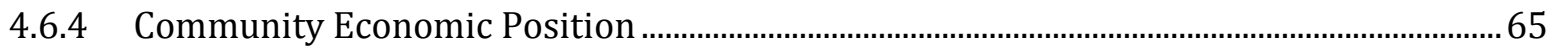

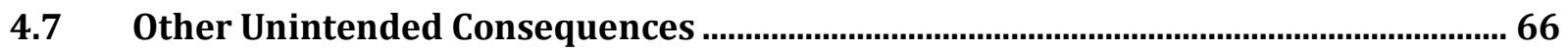

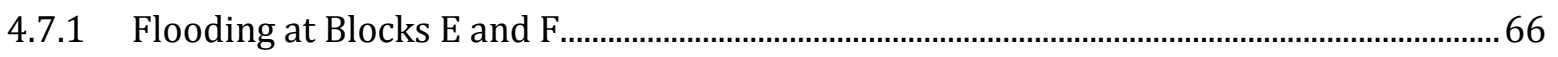

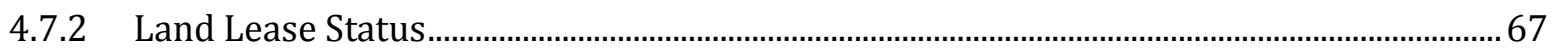

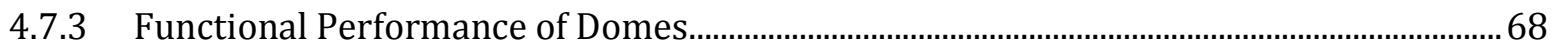

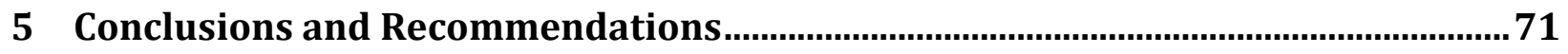

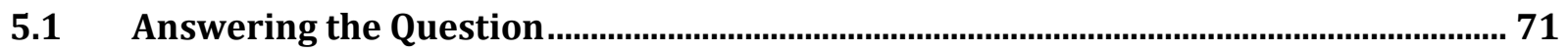

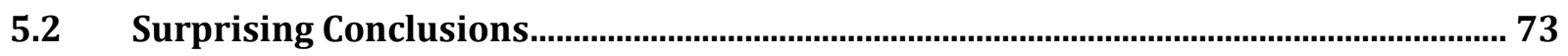

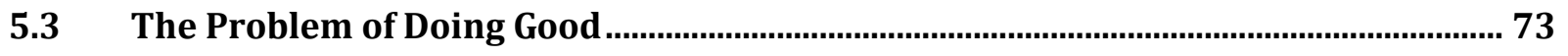

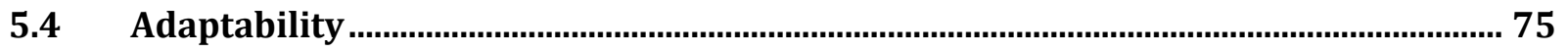

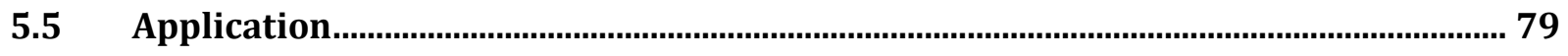

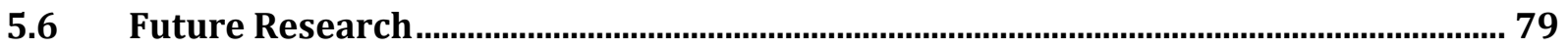

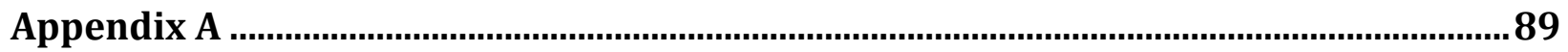




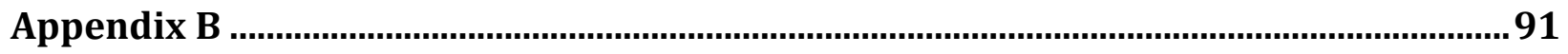

Appendix C

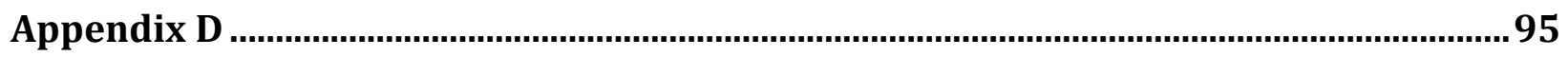

Appendix E

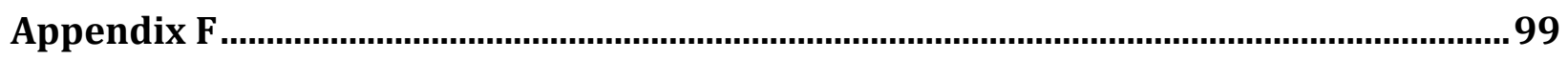




\section{LIST OF TABLES}

Table 1: Compiled Responses of Interview Guidance Question

Number Three, New Ngelepen Respondents.

Table 2: Compiled Responses of Interview Guidance Questions

Number Three, Neighboring Resident Respondents............................................... 50

Table 3: Compiled Responses of Interview Guidance Question

Number Four, New Ngelepen Respondents.............................................................. 51

Table 4: Compiled Responses of Interview Guidance Question

Number Four, Neighboring Resident Respondents .................................................... 51

Table 5: Compiled Responses of Interview Guidance Question

Number Six, New Ngelepen Respondents ................................................................ 52

Table 6: Compiled Responses of Interview Guidance Question

Number Six, Neighboring Resident Respondents ........................................................ 53

Table 7: Compiled Responses of Interview Guidance Question

Number Seven, New Ngelepen Respondents ........................................................... 63 


\section{LIST OF FIGURES}

Figure 1: Typical Confined Masonry Frame Construction in Central Java.............................. 15

Figure 2: Self-Help Expansion of Home in Progress with Exterior Plaster Application............. 16

Figure 3: Map of Indonesia, Earthquake Destruction Zone, and New Ngelepen...................... 40

Figure 4: Early Site Map for New Ngelepen Community ................................................. 45

Figure 5: Residents Stated Change in Economic Situation .............................................. 54

Figure 6: Residents Stated Change in Quality of Life .................................................... 55

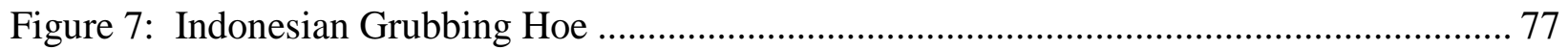

Figure 8: Traditional Road Building in Central Java........................................................ 78 


\section{INTRODUCTION}

\subsection{Rebuilding Haiti - Discovering the Problem}

On the evening of January 12, 2010, a 7.0 magnitude (Richter scale) earthquake occurred near the Haitian capital of Port-au Prince (USGS, 2010). The devastation and impact were extreme, over 220,000 lives were lost, more than 300,000 individuals were wounded, about 1.3 million people were relocated to temporary shelter, and over $\$ 7.8$ billion (US) in total damage were sustained (Haiti, "Haiti Earthquake Pdna: Assessment of Damage, Losses, General and Sectoral Needs," 2010). Two months after the earthquake a needs assessment was completed by the Government of Haiti, followed by the issuance of an action plan which addressed both recovery and development issues and called for "structural changes affecting the entire national territory.” Haitian governmental leaders pledged to “review political, economic, and social governance” (Haiti, "Action Plan for National Recovery and Development of Haiti," 2010).

It appeared that Haiti and its supporters hoped to leverage the country’s presence on the international stage to enact significant social and economic changes within the nation. One initiative, which transpired as a result of the Haitian Government's plan, coupled with monetary aid and pledges of future aid from the international community, was the "Build Back Better Communities” (BBBC) program. This program was an international design competition, an exposition, and a networking opportunity for Haitian leaders, foreign governments, nongovernmental organizations (NGOs), and potential suppliers, contractors, manufacturers, and design professionals. The intent of this initiative was to investigate the potential of alternative 
forms of permanent housing for the people of Haiti (Reading, "Building Back Better

Communities," 2010). The project board responsible for creating the competition/exposition was a consortium of organizations, including; the World Bank, The Clinton Foundation, Habitat for Humanity International, Architecture for Humanity, John McAslan + Partners, and ARUP. It was the intent of the project board to create an open portal for the submission of ideas to potentially assist in the reconstruction effort. These ideas and associated proposals would be judged and narrowed to a select group of organizations that would construct prototypes at an exposition (expo) area in Port-au Prince. The expo would allow governments, aid groups, contractors and suppliers, design professionals, and others to network and develop strategies for improved development of permanent housing in Haiti.

The design firm of Malcolm Reading and Associates of the UK was selected to manage and coordinate the Request for Proposal (RFP) and competition process. It was originally expected that the Interim Haiti Recovery Commission ${ }^{1}$ (IHRC) would play a significant role in the final stages of the expo, because the IHRC was the organization tasked with the overall coordination of recovery efforts, and its first of seven guiding principles is to "Build a Better Haiti” (Commission, 2010). In announcing the news of the Building Back Better Communities initiative, Malcolm Reading Consultants ${ }^{2}$ explains the intent of this program:

"There is broad-based support from organisations working in the field and a local team is being assembled who will manage the delivery of the Expo. We are stressing the need for local collaborations and techniques as a key element of the competition. The approach to the Expo will be holistic, focusing on home designs, incorporation of green technologies and the development of model communities." (Reading, "New Housing Competition for Haiti," 2010)

\footnotetext{
${ }^{1}$ The Interim Haiti Recovery Commission (IHRC) is directed by Haitian governmental appointees, representatives of bilateral and multilateral donors having pledged a minimum of 100 million in recovery gifts, or a minimum of 200 million in debt relief. It is co-chaired by former US president Bill Clinton, and Prime Minister Bellerive.

${ }^{2}$ Malcolm Reading Consultants is a London-based architectural consultancy firm with special emphasis in commissioning buildings, refurbishing/conserving existing buildings, and they are also a leading private organizer of architectural competitions in the UK.
} 
Prior to pursuing a graduate degree, the author was personally involved in various smallscale humanitarian aid and development projects through the organization Domes for the World. Domes for the World is a non-profit 501(c)3 NGO based in the United States which developed a low-cost housing product using monolithic concrete-reinforced dome structures. In the course of his duties at Domes for the World, the author was introduced to the Building Back Better Communities initiative, obtained a copy of the RFP, and submitted a proposal for concrete dome structures. After the first round of evaluations, which were done electronically, Domes for the World was invited to participate further by contributing to an online forum, and by submitting a more detailed proposal for evaluation pursuant to an invitation to construct a prototype at the expo to be held several months later.

The online forum was quickly filled with proposed housing solutions for Haiti. Over 350 submissions passed the initial evaluation. Prefabricated steel-stud structures, structural insulated panels (SIPs), insulated concrete forms (ICFs), and many other building technologies were presented and discussed among forum members. Some suggestions were similar in nature, but virtually every one was a new building technology for Haiti. While reviewing the proposed "solutions" in the BBBC online forum (including the reinforced concrete dome structures proposed by Domes for the World), an interesting set of observations was made concerning the nature of the proposed solutions and the motives of those organizations and individuals supporting each one.

A wide array of material types was unveiled (concrete, steel, lumber, bamboo, polystyrene, textiles, repurposed shipping containers, fiberglass, etc.). Seemingly complex design principles and methods of construction were also introduced. In some cases, conceptual solutions were produced in the form of three-dimensional images, models, and mockups, with little or no 
product testing or even prototypes. As for motives of would-be solution providers, many seemed to be "selling their wares," others were apparently propelled by humanitarian concerns; and some were simply enthusiasts taking part in the discussion.

Plagued by delays, a formal conclusion to the Build Back Better Communities competition and expo has yet to be determined. There are some obvious reasons, including the lack of a formal national government for a period of time. Regardless, the originally planned outcome has not yet been realized. In considering these aspects of the BBBC, significant questions began to form, such as:

- Will alternate technologies to current Haitian practices for structural design and construction be accepted? That is, will local engineers understand the new design basis? Will contractors implement the processes properly? Will owner-contractors adopt them?

- Will solutions that potentially require significant foreign involvement, non-native material supply, specialty equipment, and/or complicated engineering and construction practice, help Haiti holistically?

- More specifically, will adoption of these new technologies lead to continued reliance on foreign supply and reduce the potential for Haiti’s economic growth?

- In a country with massive unemployment, how will new technologies differ from traditional construction practices for job creation? Will there be more or less work opportunities?

In hindsight, it is understood that these preliminary questions were based on the assumption that the intended results of the competition - low costs, sustainable construction practices, rapid deployment, etc. - would in fact be met by the proposed solutions. 
Understanding that the competition was created to encourage those results, it is alarming that the broader social and economic impacts were not given consideration in the published criteria.

\subsection{Statement of the Problem}

Unintended consequences can result from any individual's (or organization’s) purposive actions (Merton, 1936). While the term unintended consequences has traditionally had a negative connotation, these unintended consequences are merely unanticipated outcomes

resulting from specific actions. Value judgments of an unintended consequence can be negative, positive, or neutral as seen from the perspective of each stakeholder. Negative unintended consequences are particularly troubling to practitioners in the international development arena who are trying to “do good” or otherwise promote human progress.

International development is a term used frequently by policy makers, aid workers, and business people to describe a wide range of activities that generally focus on the promotion of human progress in underdeveloped areas of the world. The definition of international development is often blurred and sometimes used interchangeably with global development, human development, or simply development. For purposes of this research, international development will refer to those aspects of the Human Development Index (HDI) as monitored by the Human Development Report (HDR), including life expectancy, education and standard of living (UNDP, 2010). International development represents a worldwide concern, as evidenced by the billions of dollars and billions of working hours contributed each year by governments, non-governmental organizations (NGOs), and private industry.

One important component of international development is to lower the cost, increase the quality, and expand the availability of safe, sustainable housing (Oyugi, 2005). This is commonly accomplished through the introduction of new housing technologies. These 
innovative technologies often incorporate materials and methods unfamiliar to the local communities. Unintended consequences almost always result from such initiatives, stemming from the relative newness of the technologies and the actors' lack of understanding cultural context and needs as defined by the local community.

Implementing a new building technology (technology transfer) into a developing country may not cause problems from the standpoint of functional performance of a structure or set of structures, although it certainly can. A successful transfer of technology to a developing nation must be viewed through a lens of sustainable national development including country-specific planning, monitoring, support of broad technology development programs, appropriateness as defined by local needs and resources, post transfer integration, training and support, proper pretransfer pairing of supplier and recipient (Ofori, "Construction Industry Development: Role of Technology Transfer," 1994). It is often argued that technology transfer is necessary for the progression of developing nations; however, the potential for unintended consequences suggests that learning from the past may provide insight on how to better select appropriate technologies for each situation, and when to implement them. There can be a significant problem of negative unintended consequences resulting from new technology implementation into the built environment in the context of international development.

\subsection{An Ethnographic Case Study}

There is much in current literature regarding fundamental theories surrounding the issue of unintended consequences of new technology implementation in the developing world, but there is a lack of discussion relating directly to economic and social aspects of the built environment. Therefore, this research followed an inductive approach utilizing an ethnographic empirical case study (Stake, 1995), specifically the reconstruction of a village in Indonesia, Ngelepen, or New 
Ngelepen as it has been renamed. Selecting a single case for study allowed in-depth understanding of context between the development practitioners and the local community.

The village of New Ngelepen was reconstructed by the small international nongovernmental organization (INGO) Domes for the World, referenced previously, a few months following the devastating earthquake of Central Java that occurred on May 27, 2006. The development practice employed by Domes for the World was a planned community approach for New Ngelepen financed with humanitarian aid funds provided by Emaar Properties ${ }^{3}$. The new construction technology used at New Ngelepen was reinforced concrete domes, known as Monolithic EcoShells ${ }^{\mathrm{TM}} 4$.

\subsubsection{Research Question}

What are the unintended social and economic consequences resulting from the implementation of new technologies introduced by a foreign NGO in the construction of the planned community New Ngelepen, Indonesia?

\subsubsection{Purpose of the Research}

The purpose of this research was to explore and answer the research question for a specific case. By selecting only one case and studying it in great depth examples of unintended consequences were discovered and understood within its local context. This was a necessary first step in the qualitative research approach required to understand the unintended consequences and provide a basis for later testing of the research findings. It is anticipated that

\footnotetext{
${ }^{3}$ Emaar Properties is a U.A.E. based development group known for building the Burj Kalifa, the tallest skyscraper in the world. Emaar Properties chose to remain anonymous until completion of the project, at which time Chairman Mohamed Ali Alabbar traveled to New Ngelepen to participate in the ribbon-cutting ceremony.

${ }^{4}$ Monolithic EcoShells are un-insulated versions of the Monolithic construction process using air-supported forms for creating reinforced concrete dome shells. The Monolithic Dome Institute of Italy, Texas is the organization that developed the technology.
} 
this initial study can be replicated using cases in other developing countries and with other building technologies. This study begins a line of research not directly addressed in past research. From the results of this and future studies, it is anticipated that conclusions may be aggregated to test specific aspects of technology transfer in the built environment of the developing world. It is hoped that eventually the new knowledge produced may be adopted by development practitioners, leading to better development approaches for the progress of individuals, communities and nations.

\subsection{Assumptions}

In laying the groundwork for this research, the following assumptions were made:

- Efforts of individuals and organizations working toward development goals are done so with positive intentions and attempted in good-faith to assist in the progression of nations and their people.

- The transfer of technology has played an important part in the development of nations, and technology transfers to the developing world will continue.

- Technologies implemented into the built environments of nations have not, and will not, always produce only positive results.

- Aspects of the developing world are similar enough that findings from this study would likely be found in replicated studies of other developing countries.

- The potential significance of this research is important to the discipline of international development, such that this study is warranted. 


\subsection{Research Exclusions}

Traditionally ethnographies seek to observe, understand, and record a broad spectrum of case elements. Nevertheless, there are items referenced in the introduction that should be excluded for clarity’s sake.

- While the situation in Haiti and the BBBC competition sparked questions resulting in this research, the New Ngelepen case represents the only location for data collection.

- Appropriateness of technologies is discussed theoretically in the literature review for this research, but an evaluation of the appropriateness of the Monolithic concrete dome technology for New Ngelepen or other locations is not part of this project.

- Sustainability will be discussed as it relates to social and economic considerations; however, the third traditional component, the environment, is not specifically part of this research.

- New technologies introduced to the built environment can encompass a number of elements. The scope of this research has been limited to two fundamental new technologies introduced in New Ngelepen: concrete dome structures, and the concept of planned communities. Other associated technologies may be noted but are not analyzed as part of this study.

\subsection{Personal Affiliation Disclosure}

The Monolithic Dome was invented and developed by David, Barry, and Randy South in the mid 1970's. These three brothers, the last of whom is the author's father, have each spent the last three decades developing this technology. As one who has grown up in the Monolithic concrete dome construction industry, and as a volunteer serving Domes for the World since 2005, it could be perceived that the author's background and participation in the New Ngelepen 
project may skew an attempt to objectively view new technologies, particularly concrete dome structures, in context of this research.

However, given that the motivation to investigate the idea of unintended social and economic consequences of new construction technologies came from a set of foundational questions not specific to any specific technology, and that the monolithic concrete dome is certainly a new technology to most of the world, the nature of the research is therefore less dependent on which new technologies are employed, so long as they are new technologies. Personal knowledge of the New Ngelepen case and the technologies used, gained from the author's personal professional involvement in the case, becomes a direct benefit to this research. Furthermore, the monolithic concrete dome is not being researched per se, but its impact (along with other technologies) as a new technology on the social and economic fabric of New Ngelepen and the surrounding community, which is the true focus of this study.

\subsection{Definitions}

Appropriate Technology: The proper selection of technology, including physical tools, artifacts, methods of accomplishing tasks, and other knowledge, for the purpose of holistically assisting in the progression of developing nations, communities, and individuals.

Built Environment: Those elements of mankind's surroundings that are man-made, and elements of nature, which are manipulated or arranged by man for living, working, and/or recreating. It includes parks, roads, utility infrastructure, buildings, etc. It also represents the aggregate of any or all components to form communities and cities. 
Community Development: The empowerment of individuals and groups in a community to make improvements to their community, supported by professionals, activists, and other individuals or organizations.

Corporate Social Responsibility: A voluntary self-regulation by private entities to promote positive impacts to employees, the environment, and consumers through the course of business practice, often including self-planning, implementing and monitoring of international norms and ethics. Closely related to the "Triple Bottom Line” (TBL) concept.

Humanitarian Aid: Assistance provided to individuals in regions where natural and manmade disasters have inflicted death, injury, property damage, disruption of critical services, and/or any other human suffering.

International Development: Efforts to improve the quality of physical, social, economic, and/or political standards of individuals, communities, and/or nations around the globe that suffer from poverty, war, inequalities, and/or depressed standards of living. Non-Governmental Organizations (NGOs): Legal entities often found in the international development and international aid arenas, typically organized as not-for-profit and operating independently of any government. In some cases NGO's may receive government funding, but such governments are not involved in day-to-day operations or even board governance of the organization.

Planned Community: A community of homes, public structures, and supporting infrastructure, which is designed and constructed on an undeveloped plot of land. Technology Transfer: The transfer of technical knowledge, methods, skills, tools and equipment to others who will use the new technology for creating goods or services for the 
recipient’s geographic area. The technology may introduce new goods and services, or it may introduce better methods of producing existing goods and services.

Unintended Consequences: Positive, negative, or neutral outcomes that were not intended from the purposeful action(s) of individuals, organizations, and governments. 


\section{REVIEW OF LITERATURE}

Very little has been published on the social and economic unintended consequences of introducing new construction technologies in the developing world. However, the question of this research lies at the intersection of several fundamental ideals, which have been studied in great detail. Therefore, a review of the following areas is essential to provide context for the New Ngelepen case and a basis for analysis.

1. Construction's role in international development

2. The developing world's traditional construction method

3. The practice of self-help construction

4. Typical approaches to international development practice

5. Technology transfer

6. Private enterprise and international development

7. Unintended Consequences

8. Sustainability

\subsection{Construction and International Development}

The construction industry plays an important role in the process of a nation's development and economic growth (Moavenzadeh, 1978). The built environment is a product of a nation’s construction industry, with the major component being shelter. Governments of developing countries have a growing need to provide shelter for the poor as populations grow simultaneously with poverty and unemployment (Rondinelli, 1990). Addressing world housing 
needs with sound policy can provide both improved shelter and employment for millions of people (Oyugi, 2005).. Notwithstanding the millions of shelter-less persons, there is also a great number of people who call flimsy miscellaneous scraps of wood, tin, and other reclaimed materials shelter (Potter, 1998). While shelters constructed of these materials are indeed a component of the built environment, this research does not consider them a viable construction technology, but rather an act borne of poverty as individuals and families seek to address critical survival needs. The built environment of developing countries is often characterized by inadequate potable water, inadequate sanitation, and irregular electricity supply (Gilbert, 2000). Other infrastructure such as roads, telecommunications networks, irrigation methods, and public facilities are also typically insufficient and/or unreliable.

\subsection{Traditional Construction}

Where shelter (housing) is the most important element of the built environment, as it pertains to survival, the majority of published literature addresses it directly. In the developing world, simple materials and methods of construction are applied in construction practice. Confined masonry frames (see Figure 1), also known as reinforced concrete (RC) frames with infill, is the dominant method of construction in much of the developing world because this process requires a low level of design expertise and construction skills (Brzev, 2008). Confined masonry frames are constructed by casting square concrete posts with minimal reinforcing. These posts are connected to similarly reinforced concrete beams above. Clay or other earthen brick is mortared as infill between the concrete frame elements. Plaster may be used to cover the exterior and or interior surfaces of the walls. Single-story structures may incorporate wood or concrete framed trusses to support clay tiles as a roofing system (typical in rural areas), or utilize flat concrete roof slabs to later support additional stories above. These structures make use of 
basic materials found in virtually every area of the world, namely cement, mild reinforcing steel, sand, basic aggregates, minimal wood components (usually just for concrete forms), clay and water. The construction process itself requires no 'heavy' equipment, and very little in the way of other tools. Unskilled labor may be employed in lieu of skilled craftsmen to perform these simple construction trades.

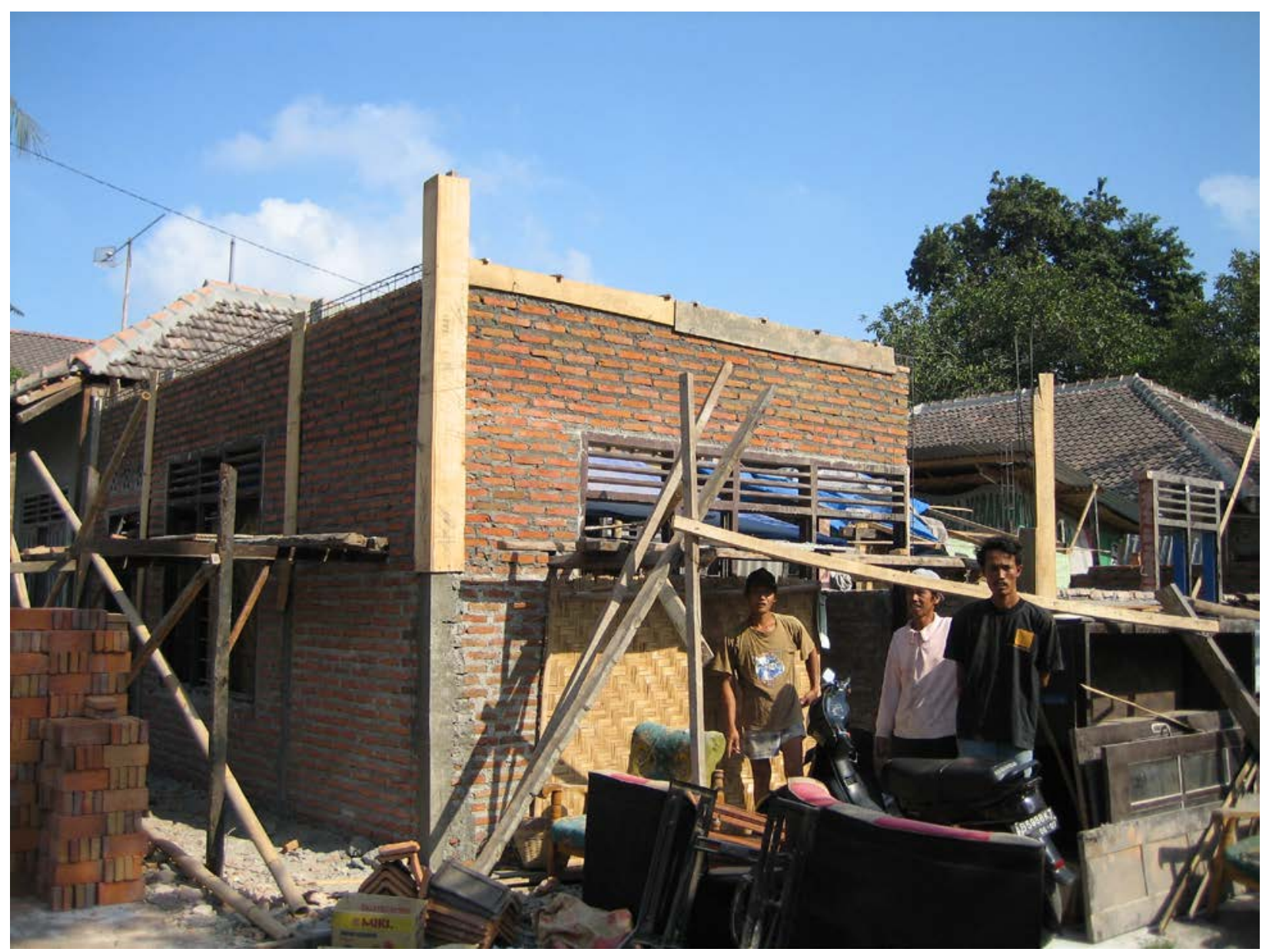

Figure 1: Typical Confined Masonry Frame Construction in Central Java 


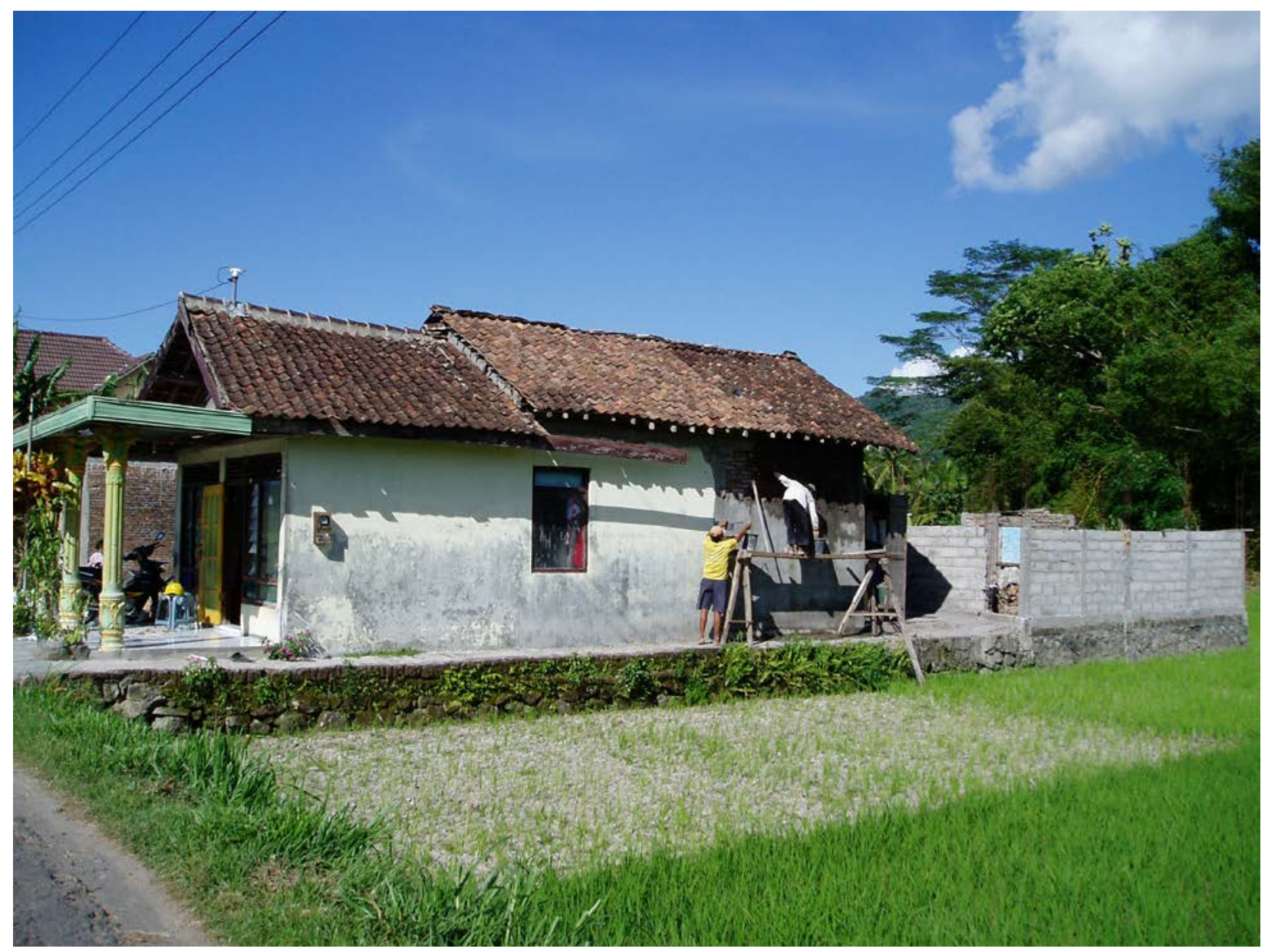

Figure 2: Self-Help Expansion of Home in Progress with Exterior Plaster Application

\subsection{Contracting and Self-Help}

Contracting in the developing world can be quite informal, with limited building code enforcement, limited or no contractor certifications, and even a lack of land-use/zoning ordinances or enforcement. Specific contract delivery methods (e.g. design-bid-build, designbuild, construction management, etc.) are in most instances non-existent.

The major practice of constructing the built environment in developing countries is the practice of self-help housing, also known as incremental construction or progressive construction (Bredenoord and van Lindert, 2010). In this approach the owner-occupants of the home build incrementally or in stages as materials can be found or purchased (see Figure 2). Often a "core" 
section of the home is initially constructed and occupied. Additional room spaces continue to be added to the home, and the self-help method of construction becomes a continual part of the household's life. The household, friends, and other family often provide necessary labor for construction of the home. This approach is the standard method for construction of shelter in developing nations; seldom is the work contracted to others. In this regard, developing nations and developed nations differ in the typical course of construction performance.

Government development agendas involving the built environment often focus on broad goals, tending to ignore the individual opportunity for self-help or incremental building in construction of single-family dwellings (Bredenoord and van Lindert, 2010). Self-help is a fractured delivery system and very hard to control or implement on a large scale. Self-help housing construction, however, is important to the social and economic development of individual households, and by extension communities and nations (Beattie, 2010). Some evidence suggests the importance and popularity of self-help comes as a result of population growth occurring faster than governments and private enterprise can plan and build communities for residents, particularly in urban centers.

A large number of participants in the development field are small organizations and are not consciously participating in multi-national policy objectives. This discontinuity has led to tensions between well-meaning NGOs and governmental bodies, each claiming to be working toward the same goals (Stiles, 2002). The ultimate lack of adequate housing, however, inspires NGOs to formulate and implement their own individual strategies for housing solutions, which can introduce potential conflicts between NGOs and governments in development. NGOs may undermine (at least to some degree) the national governments' role in a comprehensive solution, 
even while the decentralized and fractured approach is somewhat successful in providing housing (Beattie, 2010).

Considered by most as slums and squatter communities, and homelessness from the great world-wide housing shortage (Chan, Yao, and Zhao, 2003), self -help housing allows an alternative between temporary housing solutions for the poor. In the case of Trinidad, a government that experimented in granting residents of slums and squatter communities ownership or long-term leases on the land they occupied, the premise was that security of ownership would encourage households to begin the process of self-help or incremental construction of housing improvements. Yet the results have been disappointing, and the outcomes have been replaced with a community-based development model (Glenn, Labossiere, and Wolfe, 1993), suggesting that self-help construction must be the pre-selected approach by owner-occupants and paired with some type of long-term commitment to the land and community where there home is built.

\subsection{Development Approaches}

Two core approaches to development are: 1) top-down development; and 2) bottom-up development. Simplistically, these categories describe whether projects are implemented onto communities, or within communities. International development itself is nebulas in scope and difficult to define. The simplification of development to these two approaches is strictly a means to conceptualize differing contexts in which development practice occurs.

There are apparent strengths and weaknesses of top-down and bottom-up development approaches (Sabatier, 1986). Ideas of development from the 1950's to the 1980's tended toward top-down methods, generally with major involvement through nation-state policy and large market organizations (Ellis and Biggs, 2001). Top-down initiatives in development are faster to 
implement on large scales, such as reconstruction development launched from disaster response and humanitarian aid. Top-down initatives require a smaller number of people involved in the beginning stages and this development method is generally considered easier than bottom-up. However, if the people impacted by this top-down development process do not "buy-in," then development activities may struggle or fail altogether.

It is repeatedly suggested that increased community development (a method of bottom-up development) is necessary for successful implementation of new technologies (Davidson and others, 2007), (Nientied, Mhenni, and de Wit, 1990). Using three case studies from South Africa, Lizarralde illustrates some negative unintended consequences arising out of increased community participation in the implementation of housing projects (2008). These unintended consequences were not a result of using a specific technology per se, but were the result of using delivery systems that focused on community participation in the design and construction of the projects.

\subsubsection{Reconstruction}

Reconstruction development is a classic example of top-down development. Disasters are typically a consequence of failed or insufficient development practice intended to protect against and prepare for times of crisis (Collins, 2009). The negative effects of such disasters are more evident in developing nations than in developed nations. Reconstruction after disasters becomes a significant arena for development initiatives. The issue is often complicated as the practice of providing humanitarian aid after a disaster, and subsequent efforts to reconstruct following a period of aid, often bleed into one another. It becomes difficult for participants in both fields to draw a line where aid ends and reconstruction development begins. A related concern suggests that development initiatives during the aid period are ineffective because the focus of aid should 
be to return affected populations to a state of normality. And in post-disaster situations, affected groups lacking that normal state are seldom in a position to make rational development decisions (Hodgkin, 2011).

As reconstruction begins, it may still be influenced by aid organizations that fund housing and infrastructure projects, which are really developmental in nature. Furthermore, NGOs and governments often see disasters as an opportunity to change and increase standards of living for those affected. One ongoing conflict in the aftermath of the 2010 Haiti earthquake is providing adequate shelter for those left homeless, yet not spending money on short-term solutions when the same funds might be used to provide improved long-term housing.

Reconstruction provides a unique opportunity to introduce planned communities that facilitate an increase in the living standards, not just better shelter. A holistic view to development is that lasting reconstruction programs must focus on livelihoods as well as sustaining life (Ellis and Barakat, 1996). Another significant challenge in reconstruction is the lacking of formal engineering, design and construction backgrounds of development staff. Project management skills and local knowledge is sorely needed to understand and coordinate the social and cultural aspects of the region where work is being accomplished (MacRae and Hodgkin, 2011).

Another challenge in reconstruction development is to provide program planning that is flexible and adaptable to the local scenario. As with any construction project, reconstruction development contains a planning component, a design component, and a construction component.

"Planning and design development is an iterative process and requires an understanding of multiple parameters and an appreciation of the trade-offs which need to be made. Decisions made later in the project cycle may require the revision of earlier assumptions. Thus the establishment of a robust system of review and evaluation, and sufficient 
flexibility within the programme plan to be able to incorporate the findings, is an essential part of developing a reconstruction programme.” (Silva, 2010)

Coupled with the idea of a flexible and iterative planning process is the idea that such planning be accomplished in a decentralized manner, particularly in rural situations as housing itself is decentralized (Deng, 2010). Decentralizing the planning process generally allows for a closer evaluation of social and cultural implications of the development area and the program being designed.

\subsubsection{Community-Based Development}

The centralized vs. decentralized debate in development is ongoing, though most often the approaches are now decentralized. It is interesting to note that for pro-poor policies and holistic national development, democratic governance itself has many merits in decentralizing (Crook, 2000). Bottom-up, sometimes referred to as grass-roots development, seeks to decentralize development initiatives to small groups and even individuals, a common example would be offering micro loans to individual entrepreneurs. Community-based development, a bottom-up development approach, seeks to balance the efficient use of resources to positively impact small but significant numbers of people. The end goal is to develop a local community by making families and individuals more self-reliant. In community-based development, local contextual knowledge is key. Success requires individuals, NGOs and governments to listen to and understand the context in which the members of developing communities live (Polak, 2008). Case studies have illustrated that giving local organizations, formed by and accountable to local poor, greater decision-making power and financial control over development funds proves an effective option (Mitlin and Satterthwaite, 2007).

Successful community-based development programs reject a franchise system model of development (such as found in top-down methods) for a context specific learn-by-doing model 
coupled with a long-term time commitment to the development program (Mansuir and Rao, 2003). Yet there is fear of community-based approaches being susceptible to quick failure as central and local governments must share-power to some degree (Nientied, Mhenni, and de Wit, 1990). In spite of these fears, community-based programs have persisted and continue to find favor with development organizations. Within community-based development practice there exists two models, the more traditional needs-based approach, and the rapidly growing assetbased approach.

The basic development needs approach was a product of UN agencies in the 1970s (UNDP and others, 1994). Defining basic development needs is a critical and complex first step in needs-based community development (Asadi-Lari and others, 2005), but it is too often overlooked by development practitioners (Degnbol-Martinussen, 2003). Defining needs is a difficult challenge (Brandon and Lombardi, 2005). Basic human needs (Maslow, 1987) must be identified in the context of the local community and environment. Physical needs, including food, housing, safe drinking water, health care, etc., and non-physical needs such as education, social relationships, and recreation should all be considered. The non-physical elements allow people to assume personal responsibility for determining a decent life (Littig and Griessler, 2005). Once needs are successfully identified, the process of garnering community participation and supplying community organizations with needed training and resources begins. Continual program guidance, assessment and evaluation, and ultimately alterations are necessary from the supporting development organization(s) and/or government(s).

Asset based-community development (ABCD), more generically labeled strengths-based practice of development, is an approach which seeks to understand, appreciate, and mobilize individual and community talents, skills, and assets. The premise behind asset-based vs. needs- 
based development suggests that how the community is viewed (with deficiencies or with capacity) changes the way policies and programs are implemented, ultimately changing the development outcome of the community (Kretzman and McKnight, 1993). The asset-based approach requires a deep and genuine understanding of the community. Once the community and its assets are understood, ask the community what the real needs are and listen to their response (Polak, 2008). Leveraging community assets to work toward improvement of the community's own stated needs is the essence of asset-based community development. This approach is becoming the favored model in the development arena (Ennis and West, 2010). A classic example of community assets is social capital - networks and relationships within a community. While this form of capital does not inherently reflect a monetary or exchange value, research in social capital and development suggests that social relations provide opportunities for mobilizing other growth-enhancing resources. It is important to note that while social capital can be leveraged to assist in development, it can also hinder and even undermine it (Woolcock and Narayan, 2000).

Corporations participating in development from a Corporate Social Responsibility (CSR) mindset have also used ABCD with success (Fisher and others, 2009). One question raised is whether NGOs involved with international development are able to fully use the ABCD approach, seeing that they have historically been formed to seek and address needs. The passive role NGOs take in the ABCD approach may conflict with NGOs' fundamental mission and even donor agendas (Mathie and Cunningham, 2003).

A reoccurring criticism of community-based development approaches (asset or needs based) is an unequal distribution of power to individuals and groups within the community. Fundamental to community-based programs is the idea of community participation; and those 
who chose to, or are able to participate, receive power by virtue of that participation (e.g. resources utilization). This can contribute to an elitist mentality of the more powerful individuals and groups. The success of the development program, therefore, may become more dependent on the level of benevolence of the elitist groups and less from the intentions of the development organization (Mansuir and Rao, 2003).

\subsection{Technology Transfer}

Technology transfer is necessary for improving the construction industries of developing countries (Ofori, "Practice of Construction Industry Development at the Crossroads," 1994), which is necessary for improving the built environment in developing countries. The goal of proper technology transfer is the extension of a recipient's ability to use new knowledge and make development choices, as well as introduce innovations into the construction process (Abbott, 1985). It is not enough to bring in new technology; there must be a conscious focus to build up the recipients’ technological capacity through technology-specific technical skill and management training, local production of necessary materials, local access to tools and equipment, and other innovations (Ganesan and Kelsey, 2006).

Technology transfer itself is only the beginning. Full technology adoption is a long process of implementation and practice that incorporates governmental participation to support programs advancing the new technology, the technology supplier's long-term commitment to the technology and the geographic area, and the local community's commitment and motivation to learn and utilize the new technology (Ofori, "Construction Industry Development: Role of Technology Transfer," 1994). 


\subsection{Role of Private Enterprise}

Much is written about NGOs and governments, but there is a growing spotlight on the role of private enterprise. Much has also been written about the interface of "the poor" and the business world, particularly multinational corporations (MNCs). A dominant theme emerging is the notion that making goods and services available to the poor will help MNCs and enterprise gain significant profits by reaching an untapped market while simultaneously helping to bring the poor prosperity (Prahalad, 2010).

"Ending the economic isolation of poor populations and bringing them within the formal global economy will ensure that they also have the opportunity to benefit from globalization. That is the world's new entrepreneurial frontier.” (Hammond and Prahalad, 2004).

This idea suggests that the largest population distribution by wealth is the poor, or the bottom of the pyramid (BOP), represented by households living on less than a few thousand dollars per year and that there are large profits to be made by selling goods and services to this group. MCNs and other enterprises in the last decade have been approaching BOP markets in hopes of finding those profits. While there is little argument that the exchange interface between the poor and enterprise can’t facilitate development, it is suggested that treating the poor as producers for enterprise rather than consumers of enterprise will help raise actual value to the poor and create a true win-win (Karnani, 2007).

Strategic philanthropy is one way that a win-win scenario may be developed between the poor and private enterprise. Strategic philanthropy is charitable corporate philanthropy, which has a dual purpose in furthering the potential for a company’s business opportunity. Companies may develop and improve a community's road and infrastructure system, which benefits both the local residents and may allow for faster and more consistent delivery of their products. An MNC may subsidize homes for poor individuals in a community and simultaneously create a labor pool 
for company factories. Labor pool availability and sound infrastructure are examples of crucial conditions for a business competitiveness, and improving them through strategic corporate philanthropy can provide significant positive development results for the world's poorest nations (Porter and Kramer, 2002).

\subsection{Unintended Consequences}

The words unintended consequences often portray negative connotations, though unintended consequences are merely outcomes. Those whom the consequence affects may give a value judgment as to whether an outcome is positive, negative, or neutral, and often what is positive to one person may be negative to another. In any case, the outcomes by definition are unforeseen by those committing an act. The classic case of snowmobile introduction to the Scandinavian Skolt Lapps culture, or Laplanders, provides an example of how unintended social and economic outcomes to a newly implemented technology affect a society (Pelto, 1973).

Through extended intermittent contact with the group, Pelto observed both pre- and postsnowmobile life. Pelto characterized the Laplanders as egalitarian and autonomous. The native reindeer of their area were the major natural resource, and herding reindeer was done behind draught animals. Over the course of a five-year period, however, snowmobiles completely replaced draught animals, and the following unintended consequences ensued (Hall, 1975):

- Reindeer became more wild and difficult to handle because of decreased man-beast contact.

- Brutal herding techniques were developed because of high operating costs, loud noise, and high-speed snowmobiles, which caused decreased numbers of reindeer in the herds.

- Dependence on outside sources for fuel developed. 
- High cash costs of snowmobiles and fuel excluded or limited many Laplander families from participating in herding and created a strong cash dependency and debt situation for the people.

- Role reversals developed as youthfulness (ability to handle snowmobiles) became favored over experience as a requirement for herding.

- Unemployment and diversification of occupations developed during winter months for those unable to participate in herding.

- Greater speed of transportation increased the frequency of social interaction between members of the group.

Those introducing the snowmobile as a new method of transportation did not premeditate these changes, but clearly there were unintended social and economic consequences that resulted from the changes caused by the new transportation technology.

There is very little published in academic literature that identifies new technologies used in the development of the built environment, with unintended consequences of those technologies virtually unreported. However, the study of unintended consequences in international development is common, most often relating to health care and food supply (WB, 2006), (Levinsohn, McMillan, and National Bureau of Economic Research., 2005). Trade journals, however, are filled with examples of new construction technologies being implemented in the developing world, primarily in reconstruction situations. These occurrences are typically subjective success stories used to build company image and sell new building products and materials. 


\subsection{Sustainability}

The issue of sustainability and international development, as well as sustainability and construction of the built environment, is increasingly addressed in the literature. Sustainable development means that the needs of the present generation are being met without compromising future generations’ ability to meet their needs (Brutland and Khalid, 1987). On any local scale, the full scope of sustainability addresses social, economic, and environmental relationships based on social, financial, natural, built, and human capital (Arman and others, 2009). The essence of this research focuses on social and economic elements of development, with respect to the New Ngelepen case. While these elements are essential components to sustainability, there is one component - the environment - which is not part of the case analysis but still merits brief mention.

Since the late 1970s the intersection of the environment and the developing world has become an important component of debate in the development arena (Adams, 2001). Sustainable development, with the context of environmental economics, has been defined as not depleting the capital stock of natural resources (Pearce, Barbier, and Markandya, 1990). Yet there are clear links between underdeveloped communities and nations and a degrading natural environment (Dasgupta and Maler, 1990). Particularly in rural development, natural resources provide means of income for families and communities. Those communities that are unable to invest back into the environment run the risk of depleting natural resources which will ultimately increase the level of poverty for them and future generations (Reardon and Vosti, 1995). One hypothesis suggests (and is supported by empirical evidence):

“...that economic growth is likely to be accompanied by environmental degradation at low income levels, but as income grows the demand for environmental protection also tends to increase, leading to a development path 
characterized by both economic growth and environmental quality

improvements.” (Antle and Heidebrink, 1995)

As the debate continues regarding where and how sustainability fits on the international development stage, it is apparent that there is strong concern for the environment as well as significant hope that the implementation of development initiatives will in themselves promote sustainability.

\subsection{Importance of the Research}

New technologies are consistently being developed and introduced to new "emerging markets” or developing countries around the globe. While such technologies may provide a helpful advancement in human progress, are they in fact appropriate technologies? One of the goals of this research is to extend the discussion among academics and practitioners of unintended consequences arising from new construction technologies introduced in developing countries. Understanding the unintended consequences of technologies introduced to the developing world's built environment may improve the scope of pre-project assessment tools and lead to better selection and implementation processes for governments, NGOs, and private enterprise. 


\section{METHODOLOGY}

This study employed a mixed method approach of inquiry. New Ngelepen served primarily as an empirical ethnographic case study with qualitative data gathered from the following sources: in-depth interviews of project participants employed by the NGO/developer; archived construction records; interviews given with residents of New Ngelepen; and interviews with home owners living in the surrounding area. Data was coded using the computer program NVivo 9, a qualitative research analysis software package. Limited quantitative demographic data was also collected via oral surveys. This quantitative data was analyzed statistically to provide additional context for the research.

Given the nature of this research project, a qualitative case study approach allowed for an inductive method of inquiry, and as is customary with ethnographies, the purpose of the research was to identify emergent themes resulting from an extensive study of the particular bounded case (Creswell, 2006), (Strauss, 1990). Data was divided into two categories. The first category was data describing project development prior to and during the actual construction. Included in this category were the feasibility study field notes, the accompanying feasibility study report,

archived construction reports such as field personnel's progress reports, photographs, and project accounting reports generated by Domes for the World, and finally interviews with the project manager and his assistant.

The second category was information collected in the spring of 2011, approximately four years after the community was built. This data came primarily from interviews and surveys of 
New Ngelepen residents; and to provide a comparative baseline, similar interviews and surveys were given to people within one kilometer of New Ngelepen. Living in traditional shelter forms, these homeowners had no community connection to New Ngelepen.

Protecting confidentiality in the research is an ethical concern which needed to be treated carefully (Lofland, 1984). Participants from the local community were not referred to by name in the written data collected, rather by their home location (lot/block). Data was collected directly by the research team and processed by the research team only. The data is considered to be of a relatively non-sensitive nature.

\subsection{Case Definition}

As is customary with case-based ethnographies, the purpose of the research was to identify emergent themes relating to the research question, resulting from extensive study of the particular bounded case (Creswell, 2006) (Strauss, 1990). The case for this research project is defined as the design, development, and construction of the planned community known as New Ngelepen. The timeline of the case begins with the initial feasibility study and concludes with interviews given by homeowners in New Ngelepen and the surrounding communities in April and May of 2011.

\subsection{IRB Approval}

In preparation for this research project, an Application for the Use of Human Subjects was

submitted and approved by Brigham Young University’s Institutional Review Board. Given that the interviews and surveys resulted in no known risks to the subjects, and that many of the subjects were illiterate, a Request for Waiver of Modification of Consent was also submitted to and approved by the same office. In lieu of written consent, it was deemed appropriate for subjects to give their oral consent during the interview process. 


\subsection{NGO Employees}

The group responsible for implementing the technology for New Ngelepen was the U.S.based NGO, Domes for the World (DFTW). There was one full-time project manager from DFTW on location during the entire project. Additionally, there were two local Javanese residents who became salaried employees and assistants to the project manager. The balance of the project participants directly involved in construction were laborers and subcontractors hired on a wage or task basis. The project manager and one of the assistants were interviewed for the research. The interviews were recorded, transcribed, and then later coded for analysis.

\subsubsection{Wes Haws}

Wes Haws, Domes for the World's project manager for the New Ngelepen project, is a U.S. citizen who had no foreign development experience prior to his work in Indonesia. He had spent a number of the preceding years in the construction industry, including employment as a Monolithic dome contractor/project superintendent. Mr. Haws arrived on the project site shortly after Domes for the World had secured the property, and he stayed until after the ribbon-cutting ceremony for the new village and residents had moved into their new homes. He returned later in the year for a follow-up visit to check performance of domes and the village infrastructure. He has remained in contact with a few of the local people with whom he developed personal relationships during the course of the project. Mr. Haws agreed to be interviewed and have his name and involvement released as part of this research.

\subsubsection{Rudi Kuncoro}

Rudi Kuncoro was an assistant to the project manager. He was introduced to Domes for the World during the feasibility study process. Rudi was hired soon after the project was approved, approximately the same time Mr. Haws arrived in Indonesia. Rudi is a young 
Javanese local, who speaks the Indonesian language, Javanese, and English. He was born brought up in the city of Surakarta, Indonesia, about 50 kilometers from the New Ngelepen village site. Rudi was employed by Domes for the World throughout the project and was also retained periodically to gather basic information and produce photographs after construction of the village. He had no formal training or experience in development or construction prior to his employment with Domes for the World. Rudi agreed to be interviewed and have his name and involvement released as part of this research.

\subsection{Archival Sources}

Archived records and reports can provide primary and/or secondary data for an ethnographic study. For the purpose of this research, an extensive photo record of the project was obtained and analyzed as a primary data source. Written reports and documents were also obtained and were processed as secondary data sources.

\subsubsection{Photographs}

As part of the research, over 1200 digital images were collected from Domes for the World to be used in the case analysis. The pictures represented all of the images possessed by DFTW at the time of this research. Prior to the coding process, the number of images was reduced to less than 600 . Those of poor quality, duplications, and other photographs judged to have no connection to the project or even local culture were discarded.

Broad coding is the process of taking a data set and reducing it to a manageable size by comparing each image to the research question, essentially identifying whether each individual image is important to the research. During broad coding, the image count was reduced from about 600 to a practical set of 214 digital photographs. These images were coded line-by-line using the NVivo 9 software. In the line-by-line coding step each image is reviewed, and codes 
are assigned representing the image’s correlation to the research question. Images may have a single code or in some cases many different codes. Following the line-by-line coding process, the focus coding process begins. In this step each image and its codes are sorted into focus code groups. The focus codes represent those emergent elements relating to the research question.

\subsubsection{Written Reports}

Domes for the World provided the following written records, which were generated during the course of development and construction of the New Ngelepen project:

- $\quad$ The feasibility study report

- Construction status reports

- Periodic accounting reports

- The final project report

These secondary data sources were also reviewed and analyzed for connections to the research question. A coding process was applied to sort information extracted from the written reports into categories, which were later analyzed with other data sources.

\subsection{New Ngelepen Resident Interviews}

At least one adult from each household of the New Ngelepen community was interviewed in the course of this research. A head of each household (father or mother) was approached and asked to participate in the interview. An English translation of the invitation to participate is included in appendix A. Ethnographic interviewing procedures were used to develop descriptive, usually open-ended questions (Spradley, 1979), structured to expand upon the original research question. The interviews took place inside the homes, and were between 15 and 45 minutes in length. Rudi Kuncoro was hired and trained to conduct the interviews. Interviews were semi-structured using a series of open-ended guidance questions, to which 
respondents could offer multiple responses and related thoughts. Rudi asked the questions, recorded and transcribed the oral responses to each question, and then emailed the transcriptions back to the researcher. English translations of the research guidance questions used in the interview process are included in appendix B. Alphanumeric identifiers, similar to a lot-andblock system in the United States, referenced each home in the village community. The lot/block identifier of the interview respondent's home referenced each interview on separate sheets. A map of the New Ngelepen village is included in Appendix C. Interview responses to each guidance question represented a separate codeable data source. The responses were first line-by-line coded. Then, focus coding aggregated the responses into independent themes. Finally, the themes were analyzed and compiled into a table format.

\subsection{Neighboring Resident Interviews}

Using the same interview techniques as those used for New Ngelepen residents, interviews were conducted at random with heads of households in homes within a 1-kilometer radius of New Ngelepen. An aerial photograph illustrating the community area is provided in appendix D. These interviews also took place inside the homes and lasted approximately 15 to 45 minutes. Questions similar to those used in the New Ngelepen interviews were asked of each participant. An English translation of the research questions used in these interviews is included in this document as appendix E.

\subsection{Demographics}

Basic demographic information was also collected from the respondents for each household of both the New Ngelepen and the neighboring resident groups. A tabulation of occupants is included in appendix F. 


\subsubsection{New Ngelepen}

Of the 71 homes constructed in New Ngelepen, 66 had permanent residents at the time of this study. Two of the homes were vacant, as the original single occupants are now each deceased and ownership is in question. The primary occupants of the other three homes had additional shelter elsewhere and only used the dome structures periodically. Within the occupied homes, there was a total of 216 residents, with an average of 3.24 people living in each dome. The typical household consisted of a father, a mother, and one or two children. There were two cases where a mother or mother-in-law reside permanently in the home, and one case in which two families occupied a single home. Of the 66 permanently occupied homes, five families were not original recipients of the homes but were relatives of the original recipients. The other 61 households were original occupants who have lived in the homes since the construction was completed in April 2007, approximately four years.

\subsubsection{Neighboring Residents}

Of the 24 households that participated in this study, there were a total of 85 occupants, representing an average of 3.52 persons in each shelter. Like New Ngelepen, these households typically consisted of a family of 3 or 4 . There were 3 cases where an extended family member resides within the home as well. Owner-occupants of the traditional style homes had lived in the structures for an average of 27.3 years, with the minimum being 1 year, and the maximum being 65 years.

\subsection{Field Notes}

The researcher traveled to New Ngelepen, Indonesia and spent approximately one week conducting interviews, training Rudi to conduct additional interviews, and observing the village and surrounding villages. Field notes were also kept in written form and as recorded narrations. 
These observations were an important component of the data set and aided the researcher in understanding residents' lifestyles and other contexts relating to the data. The recorded observations were also incorporated in the research analysis.

\subsection{Data Triangulation}

Ethnographic studies are an inductive approach to research. Identifying themes associated to the research question requires copious amounts of data and data from multiple sources. The research intention is to triangulate emergent themes from the data. The five major data sets in this project (project participant interviews, archival records, community member interviews, neighbor interviews, and field notes) were each analyzed separately. Full data analysis took place as results from each data source were compared prompting new lines of inquiry, providing additional insight to the research question and often creating new questions. 


\section{FINDINGS}

\subsection{Expanded Case Description}

To understand the findings related to unintended consequences from the introduction of new building technologies in New Ngelepen, it is necessary to understand the design, development, and construction processes of the community in some detail. In June of 2006 Domes for the World ${ }^{5}$ was contacted by Taj Hamad, Secretary General of the World Association of Non-Governmental Associations (WANGO). WANGO had recently been contacted by a representative of the Middle Eastern development company, Emaar. Emaar's leadership offered to donate a significant amount of money to rebuilding efforts in Central Java following the catastrophic May 27, 2006 earthquake (see Figure 3).

Following the initial contact, representatives from Domes for the World and WANGO launched a three-week feasibility study on July $24^{\text {th }} 2006$ to identify opportunities to use these funds for earthquake-proof permanent housing somewhere in the region affected by the earthquake. As a result of the feasibility study, a final decision was made to design and construct a master-planned village approximately 20 kilometers southeast of Yogyakarta ${ }^{6}$, Indonesia. The new village was to be relocated less than one kilometer from the site of a massive landslide, triggered by the earthquake, which destroyed or damaged many existing homes in the area.

\footnotetext{
${ }^{5}$ Prior to 2006, Domes for the World had participated in housing development projects in Mongolia, Sudan, Ethiopia, Bolivia, Sri Lanka, and Haiti.

${ }^{6}$ Yogyakarta, or “Jogja”, is the regional center for government and commerce in the center of Indonesia's island of Java. Most NGOs active in the area post-disaster had temporary offices located in this city.
} 


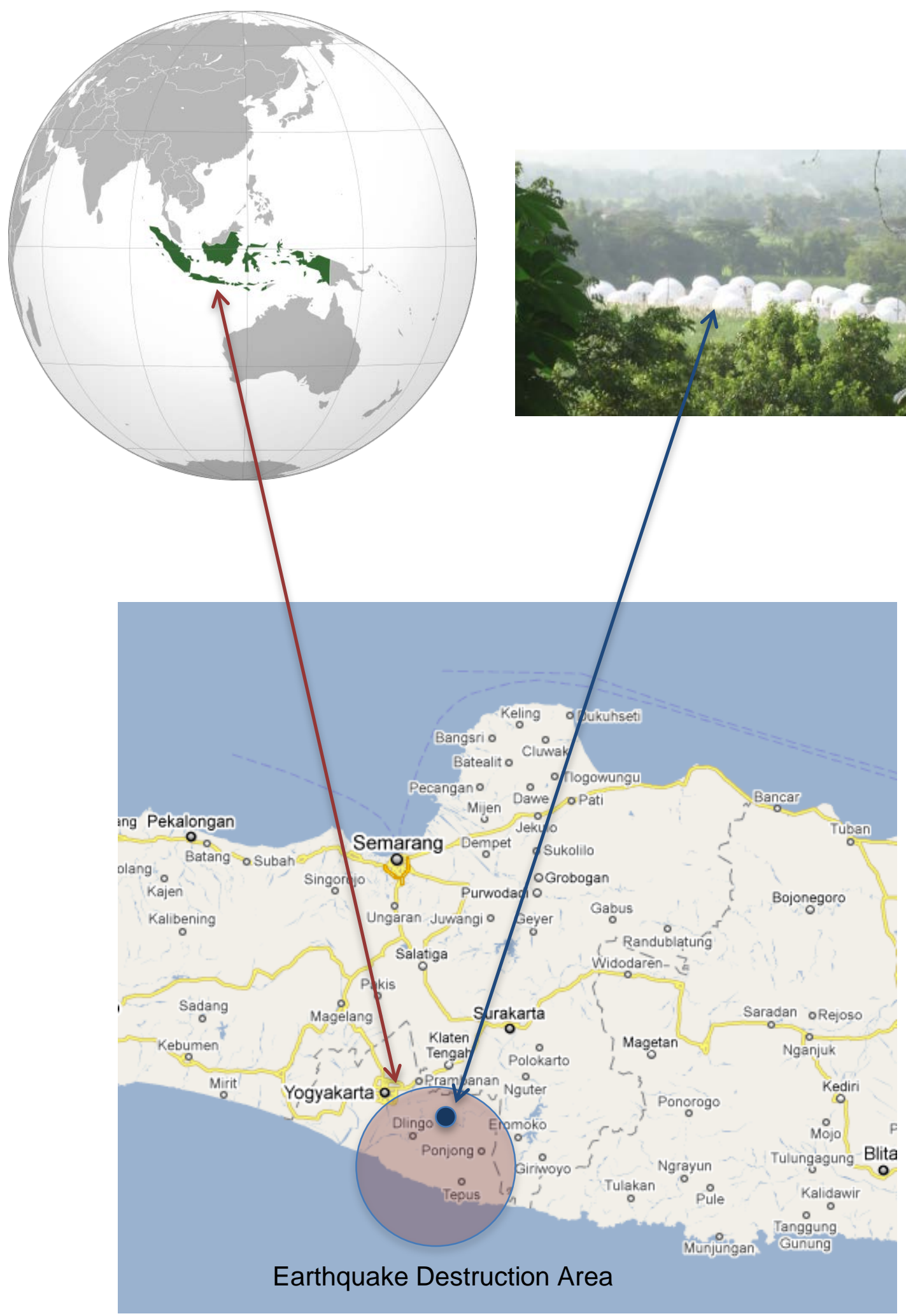

Figure 3: Map of Indonesia, Earthquake Destruction Zone, and New Ngelepen 
Named New Ngelepen, the village included 71 dome-shaped, single-family dwelling units (SFDU's), six community baths known as MCK's ${ }^{7}$, a school, a health clinic, a masjid (mosque), a public park, green space, and all associated infrastructure. All buildings were constructed of reinforced concrete, engineered to withstand earthquakes and typhoons. Within 30 days of completing the feasibility study and contracting with WANGO, Domes for the World sent Project Manager Wes Haws and their director of field operations to Yogyakarta to meet with local government officials, finalize the site location, select local material suppliers, and begin training a local labor force of approximately 400 individuals who lived in surrounding villages. These initial steps took approximately one week to complete, including the long-term lease arrangement for the land.

Immediately following these initial steps, equipment was moved on site, the land was cleared, and layouts for infrastructure and building lots commenced. By organizing local labor forces to construct roads, drill wells, install septic systems, and erect the dwelling units simultaneously, there were virtually no scheduling constraints for project. Unlike most domestic construction in the developed world, the local government required no construction-related inspections, because in this region of Indonesia there were no written codes or building authorities to enforce minimum standards. This lack of oversight was most likely a contributing factor to the extensive structural damage occasioned by the earthquake in the first place. Recognizing this lack of governmental control, Domes for the World provided engineering and design services in cooperation with professors from Gadjah Mada University, the largest university in Indonesia.

\footnotetext{
${ }^{7}$ MCK's are public buildings used by village residents for bathing, washing and toilet facilities. In rural Indonesia, individual dwelling units seldom contain bathrooms or toilet facilities.
} 
By organizing multiple crews to work on the Monolithic EcoShells ${ }^{\mathrm{TM}}$, Domes for the World was able to produce one completed unit approximately every two days. At the same time other specialized crews, trained from the local work force, were constructing roads, grading the site, building drainage ditches, erecting retaining walls, drilling wells, and installing septic systems and all network piping required for delivery of potable water to each dwelling unit. Previously, members of the community had utilized a nearby river to do laundry, to bathe, to retrieve cooking water, and to relieve themselves. The new community's modernized infrastructure introduced a higher health standard by providing clean, potable water to each dwelling unit and improved sanitation through MCK’s.

Notwithstanding a number of minor obstacles, the project was substantially complete in March of 2007, several weeks ahead of the original schedule and seven months from start of construction. The costs of community development came in significantly under the original budget, and donors were able to use the extra funds to add other amenities to the village, including a health clinic, a masjid, a public park and expanded green space. Approximately 75 percent of the donated funds used to build the community were spent on equipment, supplies and wages to local vendors and laborers, money which remained within the community. Emaar Properties, directors of Domes for the World, and representatives of WANGO all agreed that the project was a huge success. Domes for the World left the project site at the end of April, 2007.

Following completion of the project, directors of Domes for the World communicated regularly, approximately every three months, with Rudi Kuncoro and Yoss, a local building foreman who had been hired during construction. These dialogues continued in order to monitor general performance of the project and to coordinate minor construction work in other areas of the region. The total development process, beginning with the feasibility study in August of 
2006, lasted approximately 8 months, ending in March of 2007. At this point, completion of construction, including all infrastructure and buildings, was achieved.

\subsection{New Technology}

To understand the unintended consequences of new technology implementation, it is necessary to define what technologies were introduced to the village residents. The most obvious building technology was concrete domes. A less obvious technology was the planned community development approach, essentially a single development vision used to create the new village entity (Mandelker, 2010). Other technologies are noted which were not unknown to residents, but were nevertheless not utilized before the earthquake either.

\subsubsection{Monolithic EcoShells}

A building technology known as Monolithic EcoShells ${ }^{\mathrm{TM}}$, developed by the founder of Domes for the World, was used for the construction of all structures in the village. Until the construction of New Ngelepen, reinforced concrete dome structures had not been introduced to the Javanese people. This construction method employs a prefabricated flexible PVC material as an air-supported form to create the desired shape, over which reinforcing steel and concrete materials are applied. The Monolithic Dome Institute explains:

"A floor is poured, and the Airform is attached to the floor and inflated. A rebar cage is placed over the Airform's exterior and embedded in concrete. After the concrete sets, the Airform is deflated and removed from the dome's interior.

To complete the shell, that interior surface is then hand-plastered. The resulting EcoShell is extremely tough and durable. It will last for centuries with minimal maintenance. It has become our favorite low-cost structure.

In much of the developing world, labor rates are so low that it's foolish to use high-dollar equipment to apply concrete. Most people of the world know how to work with concrete. For the EcoShell, it's simply a matter of hand-applying the layers of concrete on the exterior to create the dome's shell.” (South, 2009) 
Process knowledge, skilled technician/managers, prefabricated airforms, and constant pressure fans were four major technology components "imported" for the development of this project. Other core resources such as sand, cement, reinforcing steel, labor, tools, and equipment were all locally available.

\subsubsection{Planned Communities}

The island of Java is relatively small, approximately 1,064 kilometers long and between 100 and 160 kilometers wide. With a population over 125,000,000 people, Java is one of the world's most densely populated areas (over 1,000 people per square kilometer). Yet even with this intense density, the majority of the population are rural agrarians, cultivating over two-thirds of the island's land area - mainly with wet rice ("Java," 2011).

Before it was destroyed by the 2006 earthquake, Ngelepen was a rural community of privately owned scattered lots and farm plots located in the low mountains near New Ngelepen. After the earthquake and landslide, the majority of homes were destroyed and much of the land was considered unsafe fore the purposes of rebuilding homes. Following the earthquake, the provincial government of Selman set aside a small portion of land for the rebuilding of homes by residents of the Ngelepen village. When Domes for the World became involved with the project, it was clear that the small 1.5 hectare plot contained very little land for the residents. Therefore, Architect Rick Crandall, consulting architect for Domes for the World, designed a high-density planned community to accommodate the incoming villagers as illustrated in Figure 4 (DFTW, 2006). The concept of a planned community had not been part of Javanese construction and development and represented yet another new technology implemented by Domes for the World. The actual imported technology for this development approach was mainly knowledge and professional competency. 


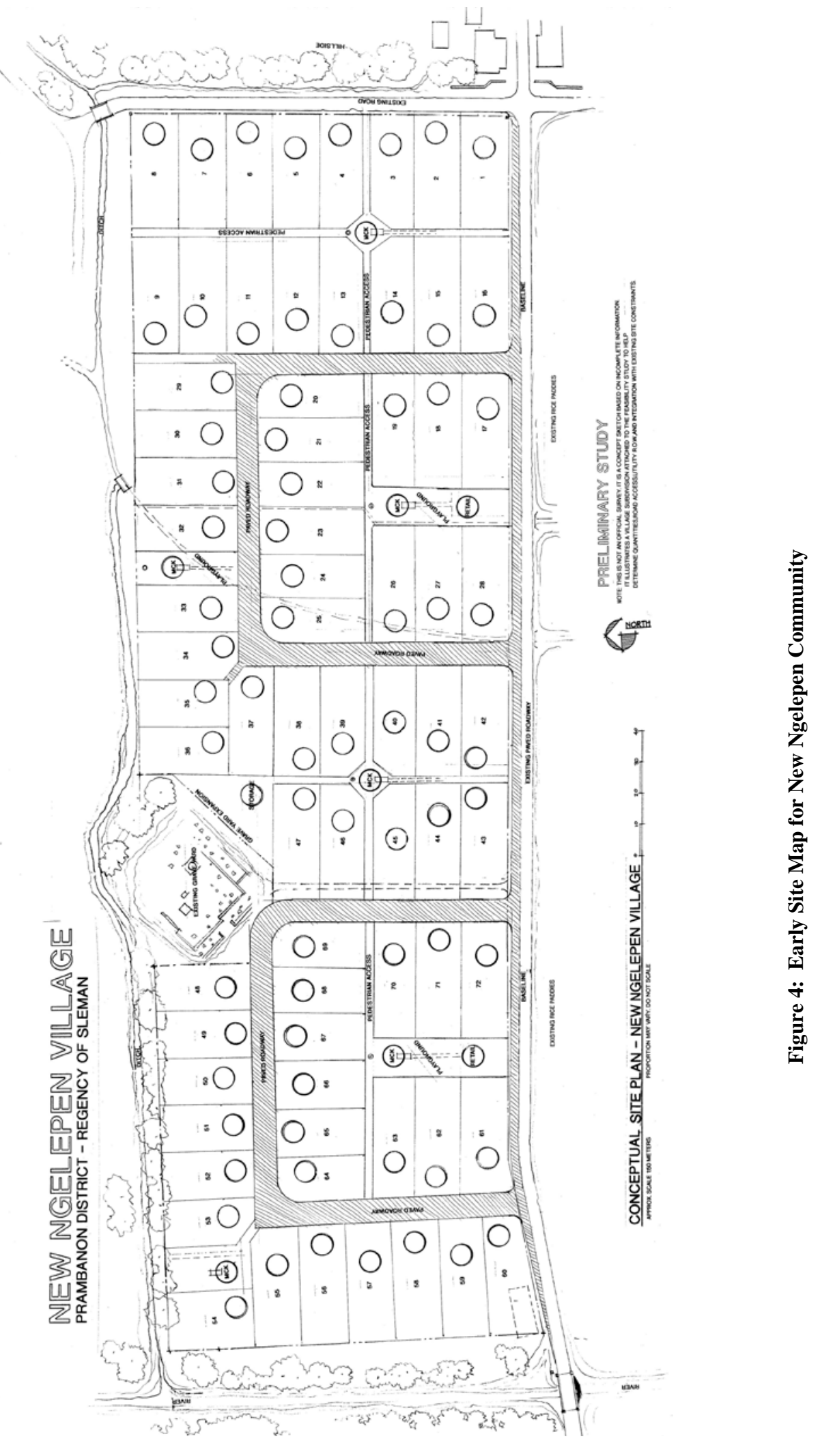




\subsubsection{Other Technologies}

There were a number of other technologies also implemented into the community which were not part of the original village of Ngelepen, such as:

- Deep water wells with electric pumps and pressure tanks

- Low pressure potable water fixtures inside each home

- Septic treatment systems for each MCK

- Wide, paved roadways with formed concrete curbs and gutters

A case could very well be made that these components represented a substantial change to the residents' lifestyle in the new village and should be considered. However, other ancillary technologies introduced with the development were considered outside the scope of this

research. It should also be noted that such technologies are currently available in many areas around central Java, and there is a high likelihood that residents have been exposed to them; whereas the concrete dome structures, and the concept of a planned community, are completely

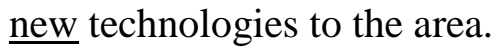

\subsection{Intended Outcomes}

Equally important in analyzing unintended consequences, is the task of identifying intended outcomes expected by Domes for the World as a result of their development activities. Interviews from project participants and analysis of secondary documents illustrate the following anticipated outcomes:

- A model community of disaster-safe, permanent, economical, sanitary and efficient construction standards

- Potable water piped into each home

- Introduction of proper sanitation systems 
- Introduction of Monolithic EcoShell ${ }^{\mathrm{TM}}$ structures, and training of the local workforce for technology transfer

- Provisions for more reliable electricity

- Production of improved roads and walkways

- Provisions for private garden areas on each lot

- Design of the new community for future automobile use

- Local culture to remain intact throughout development process

- Development of a centralized village store area

- Inclusion of home owners' sweat equity in each home

Analysis of whether these intended outcomes were met, and to what extent, is beyond the scope of this research, but understanding what was intended is critical in separating those outcomes from the unintended consequences, the main goal of this research. It was discovered that in some cases where intended outcomes were not met, specific unintended consequences were observed. These, as they appear in this chapter, will be noted.

\subsection{Key Interview Responses}

A significant amount of data was amassed during the course of this research project. Through the broad coding process of local interview transcripts, compiled responses to interview guidance questions numbered three, four, six, eleven, and twelve provided the most relevant information to this inquiry and some of the most insightful data in these findings. These selected responses are summarized and tabulated in the following sections.

\subsubsection{Guidance Question Three}

Question three prompted participants to identify significant differences between the New Ngelepen community and a "traditional" community. Traditional in this sense was any non- 
dome community in this area known as the upper Bantul Plain. The 66 New Ngelepen residentrespondents were each asked the question "How is living in this community different from living in a traditional community?” There were a total of 120 separate response elements, or an average of 1.82 independent responses per participant. An alternate question asked of those 24 respondents living in households in the surrounding area was, "Do you think it is different living in a dome community?” This produced a total of 39 separate response elements, or 1.63 independent responses per participant (see Tables 1 and 2).

\subsubsection{Guidance Question Four}

The fourth question, "What would you change about your community,” was asked to both groups of respondents. The intent was to learn the two groups identified as similar and different. The New Ngelepen residents produced 69 elements, averaging1.05 responses per participant. The neighboring residents produced 28 elements, 1.17 responses per participant (see Tables 3 and 4).

\subsubsection{Guidance Question Six}

Comparing perceptions of the New Ngelepen villagers with those of the neighboring communities was accomplished with question six. The 66 New Ngelepen resident respondents were asked “How do others view you, now that you live in the community?” There were 88 response components, 1.33 average items suggested by each participant. The neighboring group was asked "How do you view those living in the dome community?" which produced 36 responses, or 1.5 elements per participant (see Tables 5 and 6). 
Table 1: Compiled Responses of Interview Guidance Question Number Three, New Ngelepen Respondents

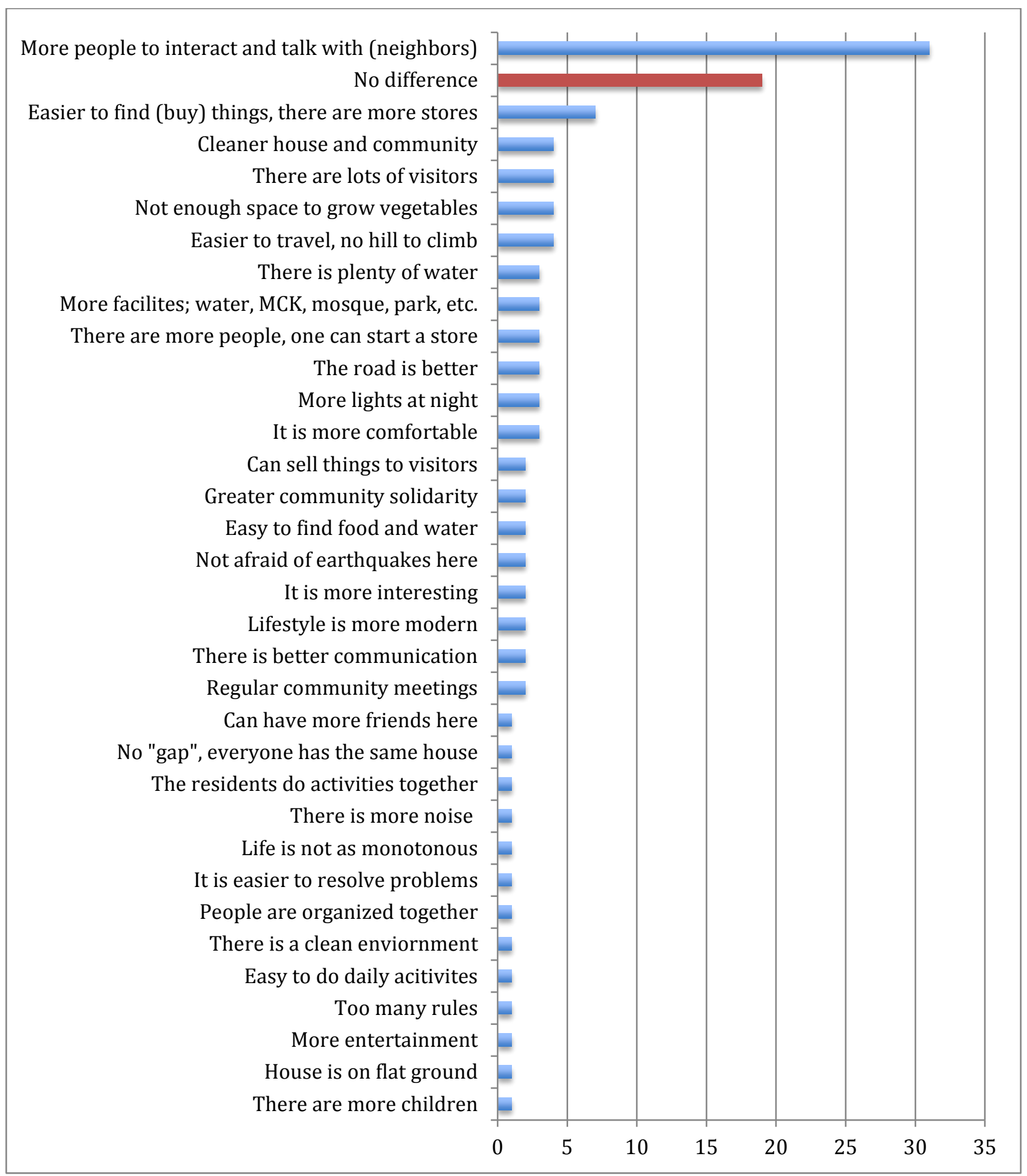


Table 2: Compiled Responses of Interview Guidance Questions Number Three, Neighboring Resident Respondents

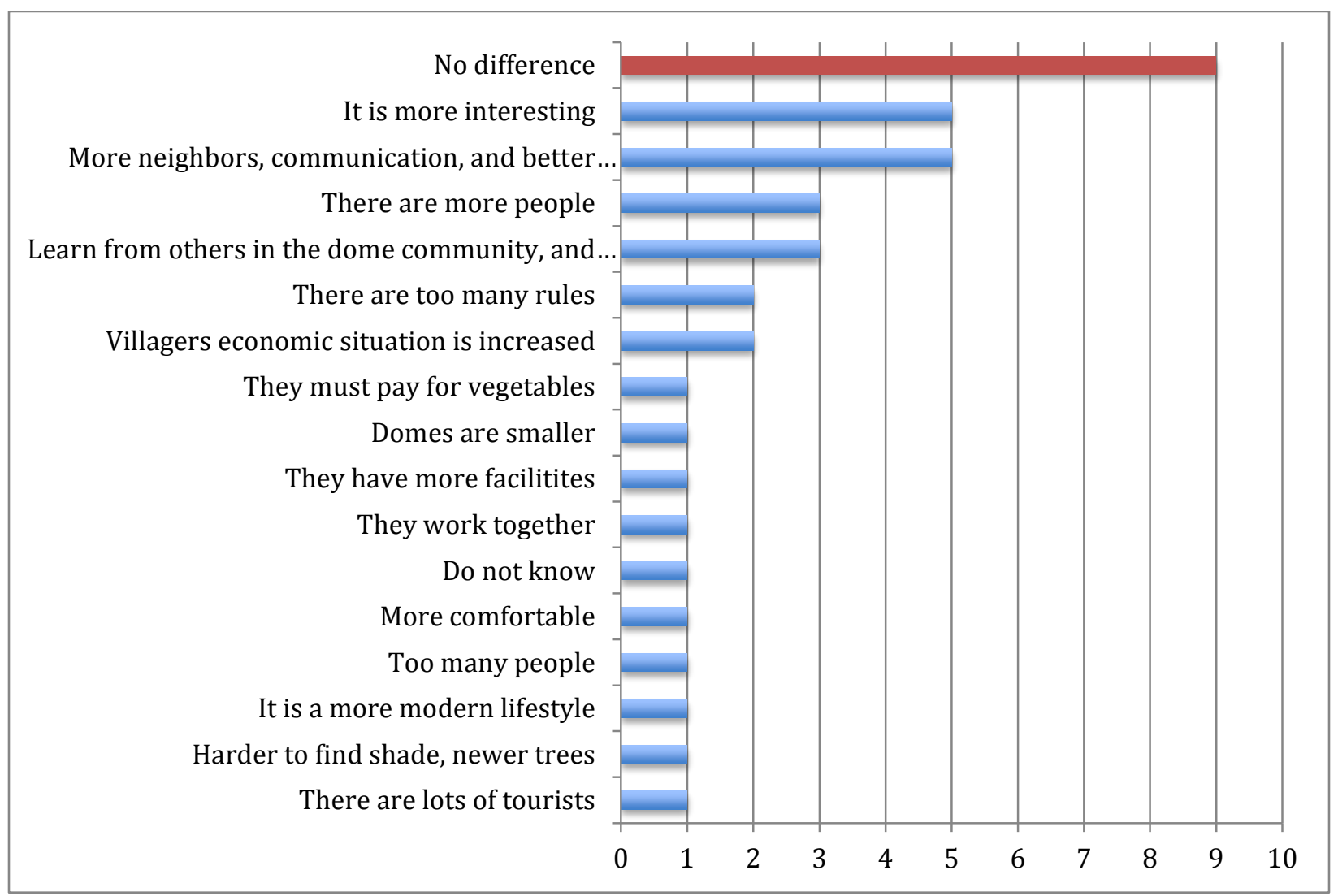


Table 3: Compiled Responses of Interview Guidance Question Number Four, New Ngelepen Respondents

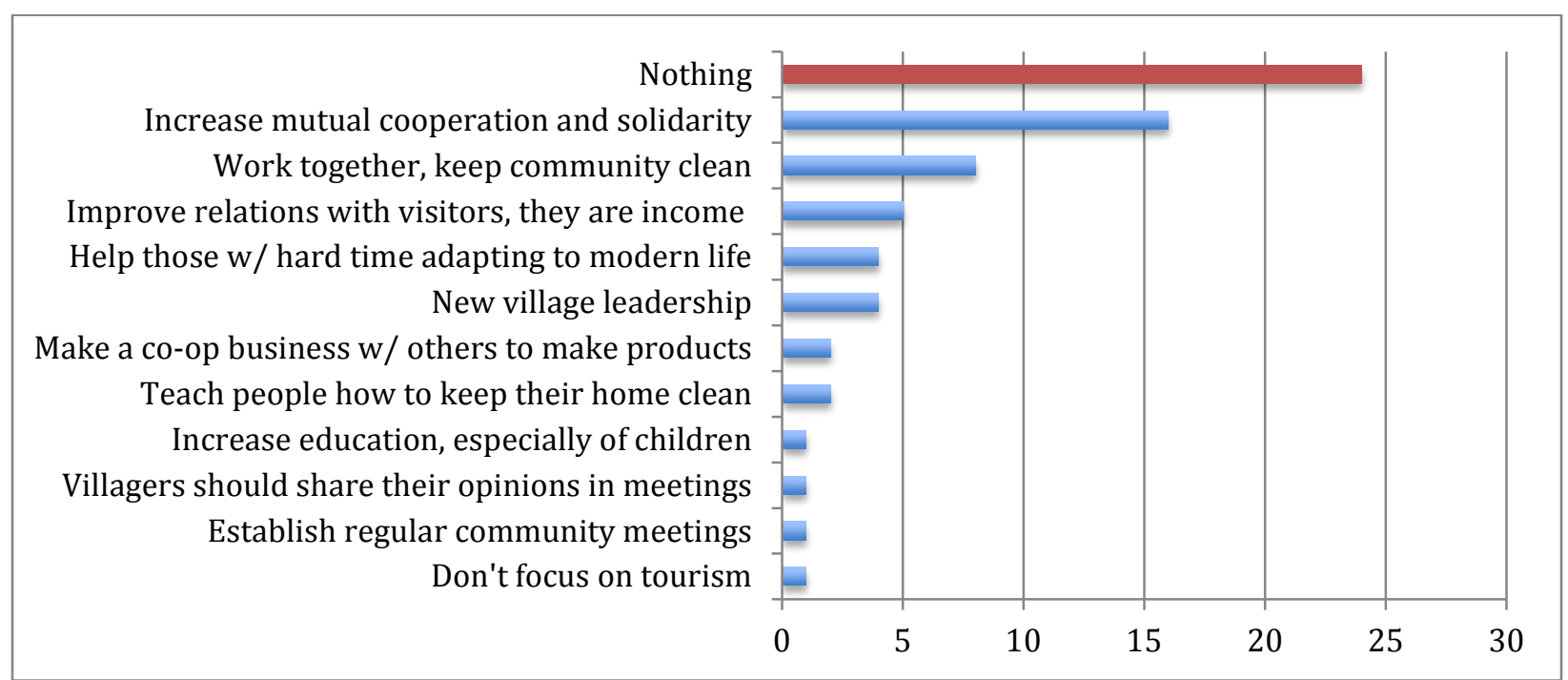

Table 4: Compiled Responses of Interview Guidance Question Number Four, Neighboring Resident Respondents

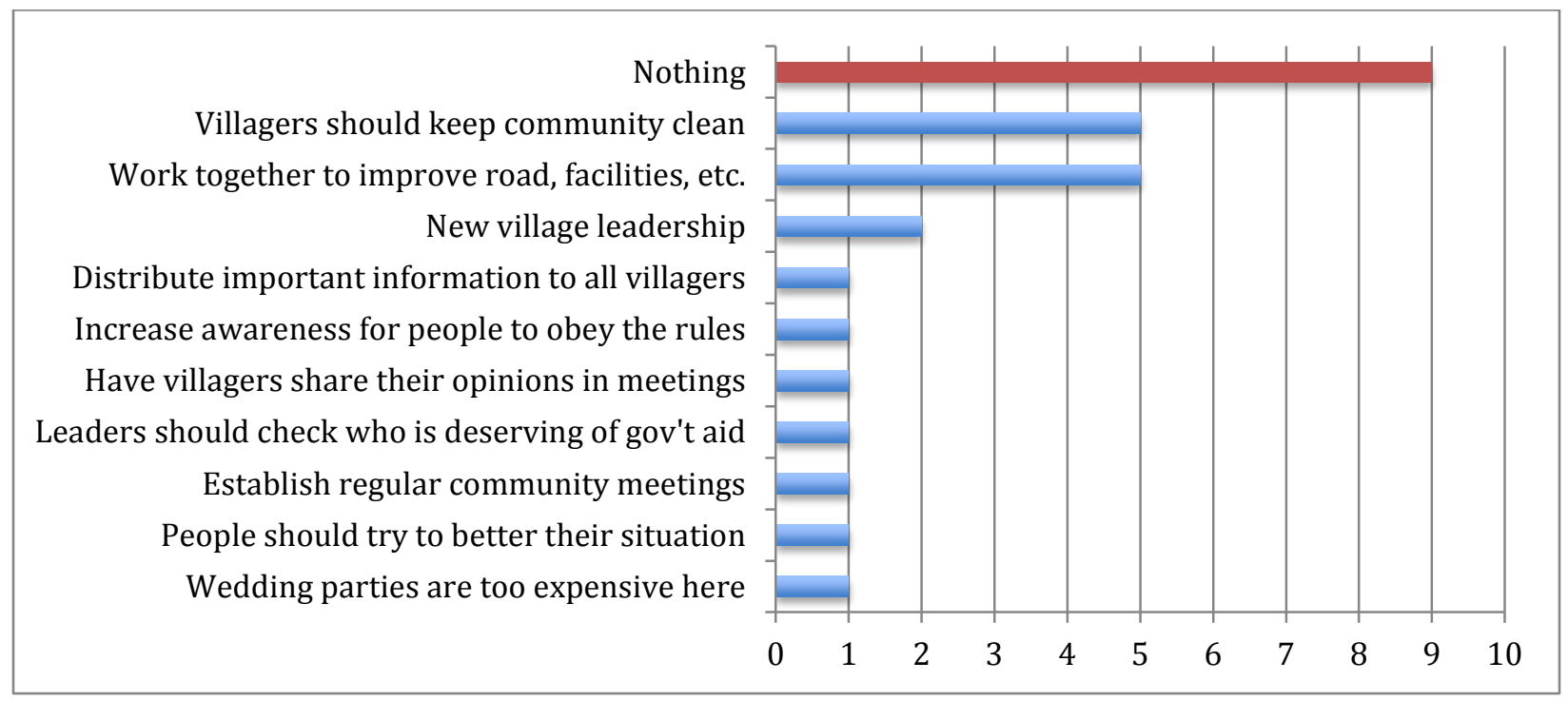


Table 5: Compiled Responses of Interview Guidance Question Number Six, New Ngelepen Respondents

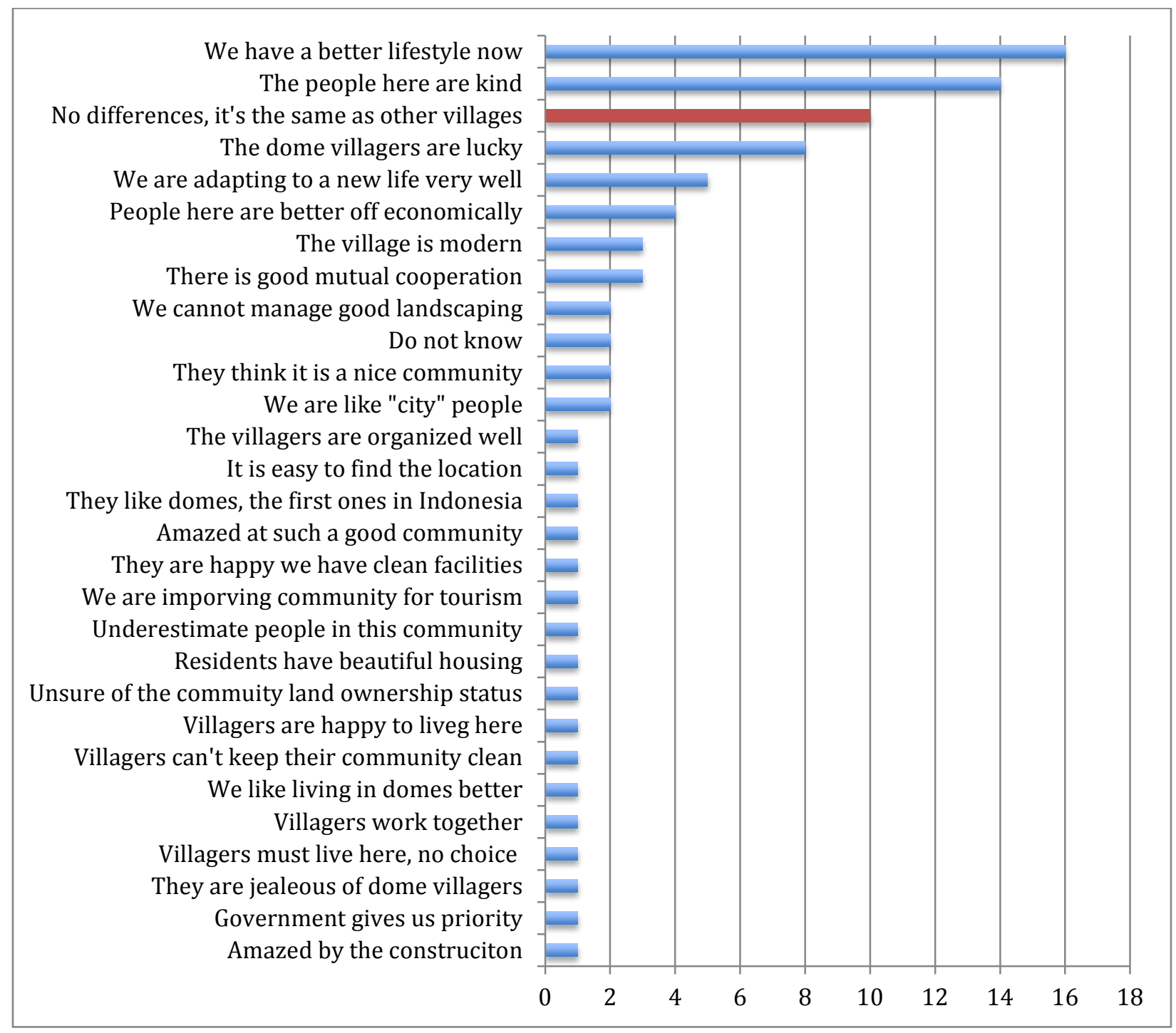


Table 6: Compiled Responses of Interview Guidance Question Number Six, Neighboring Resident Respondents

They have increased their economic status No differences, it's the same as other villages

They are lucky to live in nice houses They can meet and learn form visitors

They have better entreprenuership

They are nice and kind

They are less comfortable, they must lease the land

They have lots of activities

They are happy

They adapt well to new life

They have a better lifestyle than other villages

They have a modern lifestyle

They have a nice road

They live comfortable

They work together to progress their situation

They have more activities for women

The dome community is healthier

The dome community is more peacful

Relationships in dome community are better

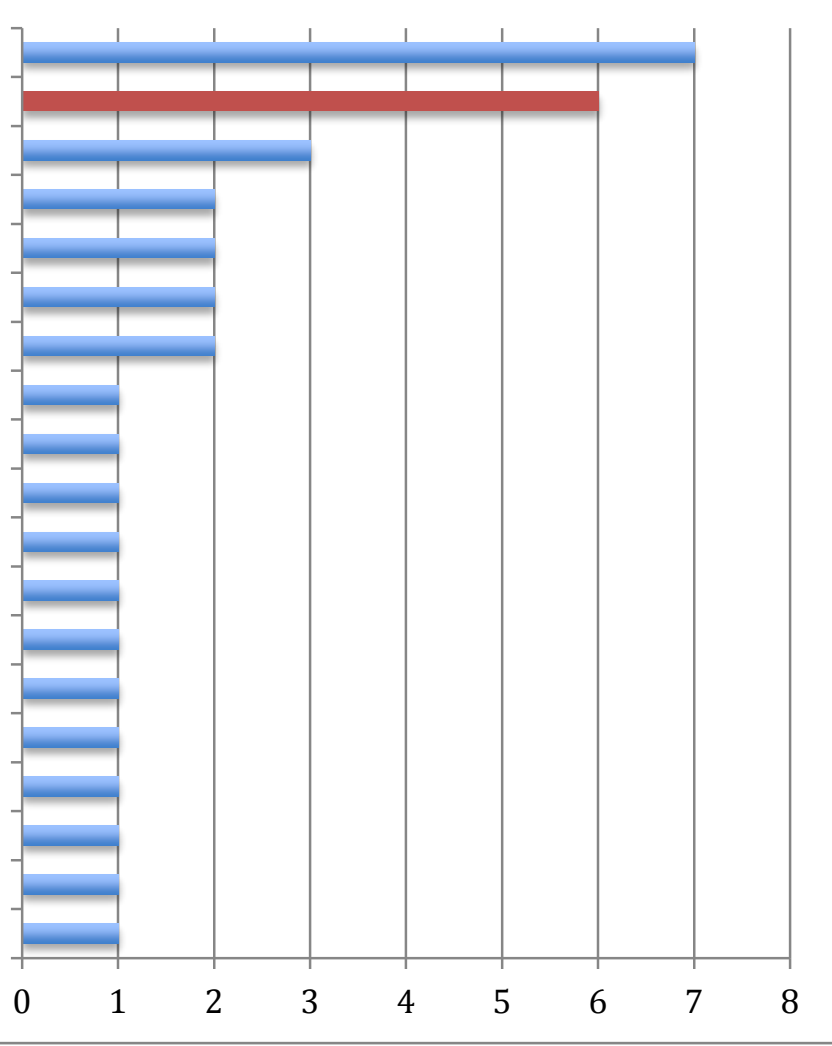

\subsubsection{Guidance Question Eleven}

Question number eleven was asked only to New Ngelepen participants to understand directly their perception of any change in personal/familial financial position, and why. This question was not open ended, but the respondents were encouraged to explain their answers. The responses noted here have been simply categorized as better, worse, the same; or in one case a respondent could not decide, because some things were better and some things were worse (see Figure 5). 


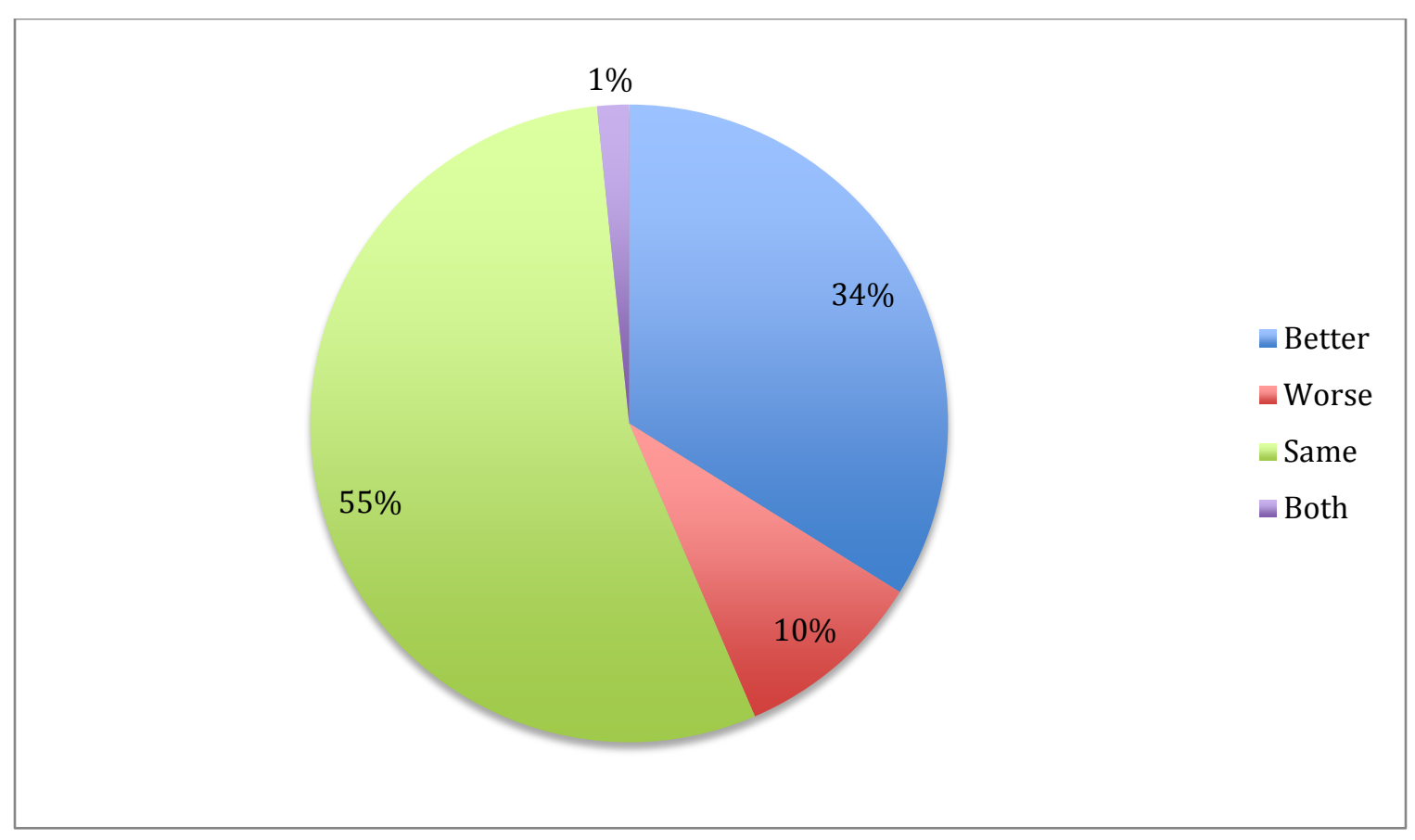

Figure 5: Residents Stated Change in Economic Situation

\subsubsection{Guidance Question Twelve}

New Ngelepen participants were also asked the direct question "Has the quality of life gone up or down since moving into this community?” Quality of life (QOF) is a term used to measure human experience, of which social and economic components are significant portions (Costanza and others, 2007). Given the foundational nature of this study, the responses from this question were simply to provide a relative measure of overall satisfaction or dissatisfaction for the community (see Figure 6). 


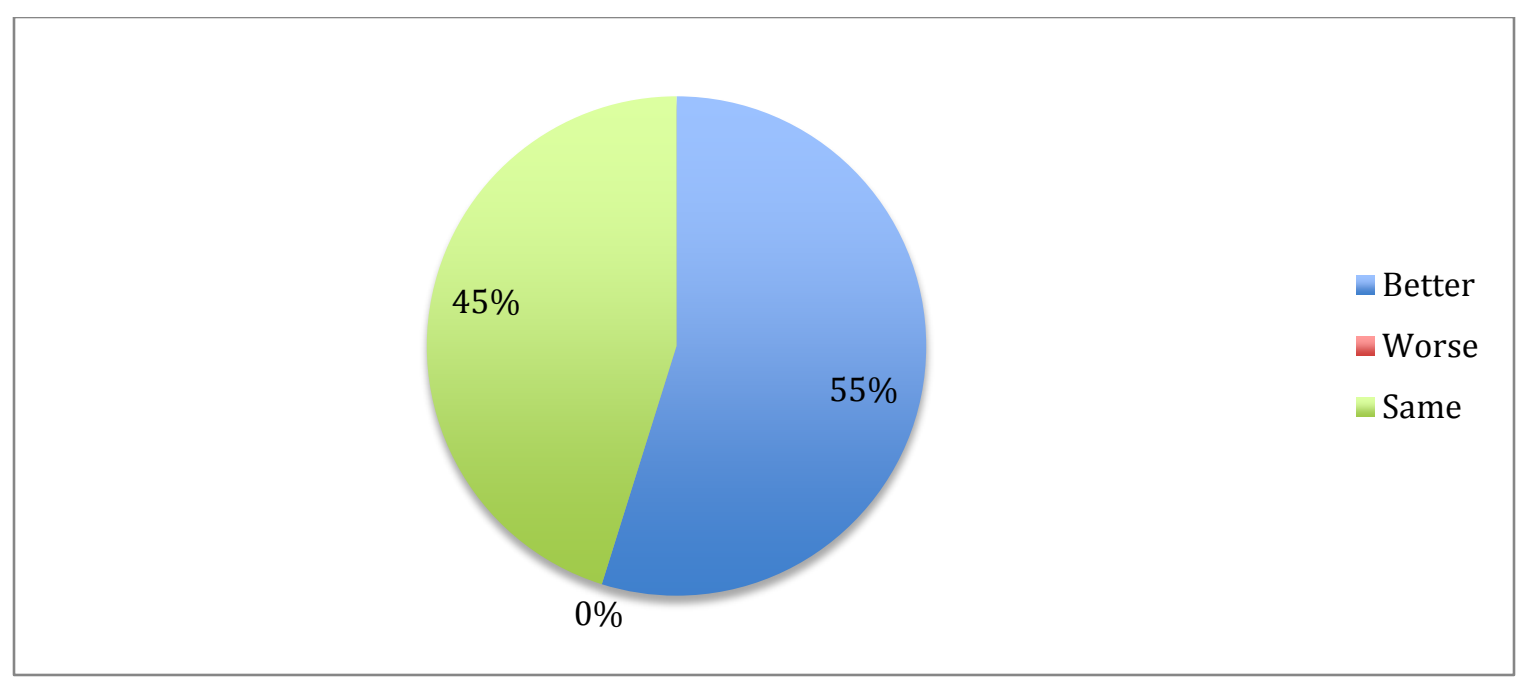

Figure 6: Residents Stated Change in Quality of Life

These tabulated responses, coupled with the other data sources, illustrate significant unintended social and economic consequences as a result of Domes for the World's development action. Other unintended consequences relating to the functional performance of the structures individually and of the built community collectively are also apparent. Unintended functional consequences are not specifically part of this research, but will be noted briefly.

\subsection{Unintended Social Consequences}

The term "social" refers to the conscious and unconscious interactions of and among people (individuals, families, groups, etc.). The introduction of new construction technology (specifically Monolithic EcoShells ${ }^{\mathrm{TM}}$ and the planned community concept) into this rural Javanese location produced a number of unintended consequences. Social relationships, community solidarity, intercommunity social status, increased leisure time, and more concentrated government development progress were the significant social findings. 


\subsubsection{Socializing}

Agrarian households predominantly settled the old Ngelepen village site and most of central Java. Rice fields and other small plantations (as they are called locally) of vegetables and native food plants surround each home. The tropical climate encourages growth of bamboo, banana and many other types of useful vegetation. The scattered plots of land, coupled with dense vegetation, isolate households from each other. It is not uncommon for families, particularly parents, to have little or no regular social interaction with neighbors in the surrounding area. Furthermore, public infrastructure such as paved roads and streetlights seldom penetrate the rural landscape. It is a subsistence lifestyle for most, with routine activities occurring during the 12 or 13 regular sunlit hours of each day. In three interviews of New Ngelepen residents, the brightness and adequacy of interior lighting inside the domes (which were plastered and painted white inside) was cited as reason they preferred living in the new structures to traditional homes. Other interviews suggested that street lighting was a reason residents could congregate and converse after the day's normal activities. One respondent said, "I have communication with others at night, because I am close I can visit. In my other home, when night came, we lived far from neighbors and went to bed after it got dark.” Another respondent stated, "When I lived in the mountains, I could visit only one family a day because I had to walk a long way. I know everyone in the whole village in New Ngelepen... it is easier to visit.”

The most common response from New Ngelepen residents, when asked about the difference between the new community and traditional communities, was that there were more neighbors, people to talk to and interact with. The third most common response from those interviewed from outside the community, when asked a similar question, was that there were 
more neighbors, communication, and better relationships in New Ngelepen. It appears that in addition to close physical proximity, residents are developing close social relationships.

Observing the surrounding communities one could see children near most of the homes. Children were often entertaining themselves with simple toys and other random objects. In the New Ngelepen community, however, there is a park area, a playground, and lines painted on one road for some competitive sport. In most visits to the community, children could be found playing sports, wrestling, and participating in other activities together. One resident interviewed said, "I feel more comfortable living in this community because there are more people to talk with and more children. It can make the children grow better because they can have more friends to play and talk with.”

\subsubsection{Community Solidarity}

Solidarity is unity among people with a common interest. The New Ngelepen community has a unique appearance, was developed under unique circumstances, and has become the center of much attention in the region. This has no doubt aided the village in assuming a specific community identity, in the true sense. It appears that community solidarity is important to these people. Both groups interviewed listed improving cooperation, solidarity, and specific forms of community work projects as things they would change about their community (guidance question \#4). One interview participant from the surrounding area stated that "people in the dome community work together very well to enhance the progress of the village.” Another interview participant, from New Ngelepen, stated, “There are many community activities to

clean the area, but when I lived on the mountain before the earthquake, we never got together to do that. I like the activities down here.” 
In over a dozen locations throughout the community there are placed small blue plastic bins, grouped in sets of three, located intermittently on the side of village streets. They are for inorganic waste, organic waste, and recyclables. New Ngelepen is the only community in the region where these are found. This is a program sponsored by the local government. Adjacent to the community is a small wooden shack where workers smash plastic bottles as part of a recycling program. On one occasion, during the fieldwork, an empty plastic water bottle was deposited in a recyclables bin. The researcher was only a few steps away when a boy opened the bin, grabbed the bottle, and rode his bike down to the "recycling depot" to deliver the find.

\subsubsection{Progress Prompts Progress}

Many people in developed countries would say that increased social relationships, more leisure time, better access to water and sanitation facilities, etc., would be considered progress. It appears that such progress has prompted additional progress. It has already been illustrated that progress in terms of government waste collection and even recycling programs has been implemented in New Ngelepen. Other government programs have followed as well, such as a gas cooking initiative.

It is typical for Indonesian families to cook their meals using wood-fueled fires. To keep heat and smoke out of the main part of homes, kitchens are typically erected as independent structures or as a partial open room connected to the exterior wall of a home. In other cases still, kitchens consist simply of open fires outside the home. The design of the new dome homes incorporated a kitchen area for preparing and serving food but expressly excluded a cooking area within the home. Cooking was to be done outside in the traditional manner. Burns and smoke inhalation have been common health problems in the developing world, and many development initiatives have attempted to educate people about these dangers and to propose alternative 
methods of cooking. For example, the regional government in central Java introduced a program for cooking with propane gas burners. Residents of New Ngelepen were offered free gas stoves so cooking could be safer, cleaner, and done inside their small kitchens. Others in the neighboring communities have not been offered the same program.

The regional government has introduced two other development initiatives. One is establishing a women's sewing enterprise. One interview participant shared the following:

"The government gave sewing machines to those in the dome community, but not to other communities...There are more than three sewing machines kept in one dome. They have workshops on how to make clothes - the government puts on the workshops. Last time they had the sewing workshops for one month. Many believe this community has priority to get government assistance.”

The other initiative was the construction of a community cow barn for residents of New Ngelepen. The government constructed a multiple-stall barn, and each resident who has a cow may keep it inside the barn. Residents gather feed, often the stalks from rice that has recently been hand thrashed, and complete the daily task of transporting and feeding their cow. The relocation of cows from small personal plots was a development program to promote better community health. Two of those interviewed in the neighboring communities suggested that they had plans to move their livestock from their homes, citing health and foul odors as the primary reasons. This practice has also been replicated in other communities surrounding New Ngelepen. It is evident from these examples that New Ngelepen has had more opportunities than surrounding communities to adopt development programs and has responded very positively to the different programs/initiatives.

One interesting social response to the changes and successes of New Ngelepen is the potential for an increase in social status of members in the new community. Many neighboring community members who were interviewed believe that the new dome community is really no 
different than the old community or surrounding communities. Yet the most common response from New Ngelepen residents was that others see them as having a better lifestyle. One dome community resident said; "Some people who are from another area think the [people in the] dome area are like people in the city. They think the dome community has a better lifestyle...some are jealous.” Evidently there could be a conflict if surrounding community members see residents of New Ngelepen as being equal in status with them, while the residents of New Ngelepen believe outsiders see them as having a better life.

\subsection{Unintended Economic Consequences}

The economics of a rural agrarian society located in a developing country are very basic compared to more complicated economic conditions of developed countries. Subsistence lifestyles, predominant in central Java, generally produce little in the way of disposable income not required for basic human needs. The typical household in central Java grows rice, the staple food source, and sells it to a local commodities buyer. Other crops are raised and harvested on personal land to supplement a family's food supply and to feed personal livestock. Wealthy households may own a small motor-scooter for transportation, while most people walk. During the field study it was common to see individuals 50-70 years old walking or hiking dirt roads carrying packs of rice stalks for cattle feed. Travel outside the local community was seldom necessary. Those who do not have farmland of their own would typically be hired as a farm worker for the few individuals with large plots of land.

The planned community New Ngelepen was essentially developed and delivered turnkey. The new residents were relocated from their original plots of land (most plots being rendered unsuitable for crop cultivation or home reconstruction by the earthquake and ensuing landslide) to small lots in the planned community. These lots were less than 1,000 square feet in area. The 
development project was a new technology for central Java and certainly a new "look" for the region. The delivery method, the small lot size, and the unique architecture led to three distinct economic shifts for the residents. The first was a partial failure of technology transfer, resulting in a localized disruption of the self-help construction process. The second was an increased marketplace for village residents, and the third was the spontaneous creation of a tourism market.

\subsubsection{Technology Transfer}

Domes for the World's archival records indicate that technology transfer of the monolithic concrete dome construction process was a significant planned outcome. True transfer requires local access to specialized equipment and education of the local workforce to autonomously replicate the process. Specialized equipment requirements were very minimal, and required equipment had been shipped in from the United States. But it does not mean there is local access. Additionally, there were 80 structures constructed in the community and hundreds participated in the process, gaining experience and training in the construction methods. But this does not guarantee that training was sufficient for continued independent production as required by true technology transfer.

Interviews with Rudi and Mr. Haws indicate that following the New Ngelepen development 15 additional structures were built on the Bantual Plain by a small group of individuals who had been hired by Domes for the World. In the three years after this project was completed, one primary school was constructed in a neighboring village, and a second school is currently underway on the island of Sumatra. The researcher visited the completed school and learned that the project includes two structural domes that were built without the use of the specialized air forms. Instead, the builders adapted traditional plywood forms into the dome

shape and then applied reinforcing steel and concrete just like the process used for EcoShells ${ }^{\mathrm{TM}}$. 
Without financial support or direct access to specialized equipment from Domes for the World, the primary school is the only documented case suggesting technology transfer has been accomplished. Even so, the local people have already modified the technology to better suit local conditions, which is often a sign that technology has been successfully transferred. But evaluating all aspects suggests that the goal of technology transfer was not accomplished, at least not to the extent intended.

Residents interviewed have commented that the dome structures require less maintenance. They have also noted however, three reoccurring problems in the structures' performance:

- Unsightly cracking of the homes’ top exterior plaster layers

- Insufficient ventable area for proper air circulation

- The use of poor quality wood for doors and windows, and/or the lack of exterior protective weather canopies over the doors and windows The potential unintended economic consequence associated with the incomplete technology transfer has begun to show itself as residents have attempted to expand their homes. When asked, “What would you change about your home?” respondents offered 105 suggestions that when tabulated illustrate the potential problems residents currently have (see Table 7). It is not clear whether there will be cost effective solutions for the residents? 
Table 7: Compiled Responses of Interview Guidance Question Number Seven, New Ngelepen Respondents

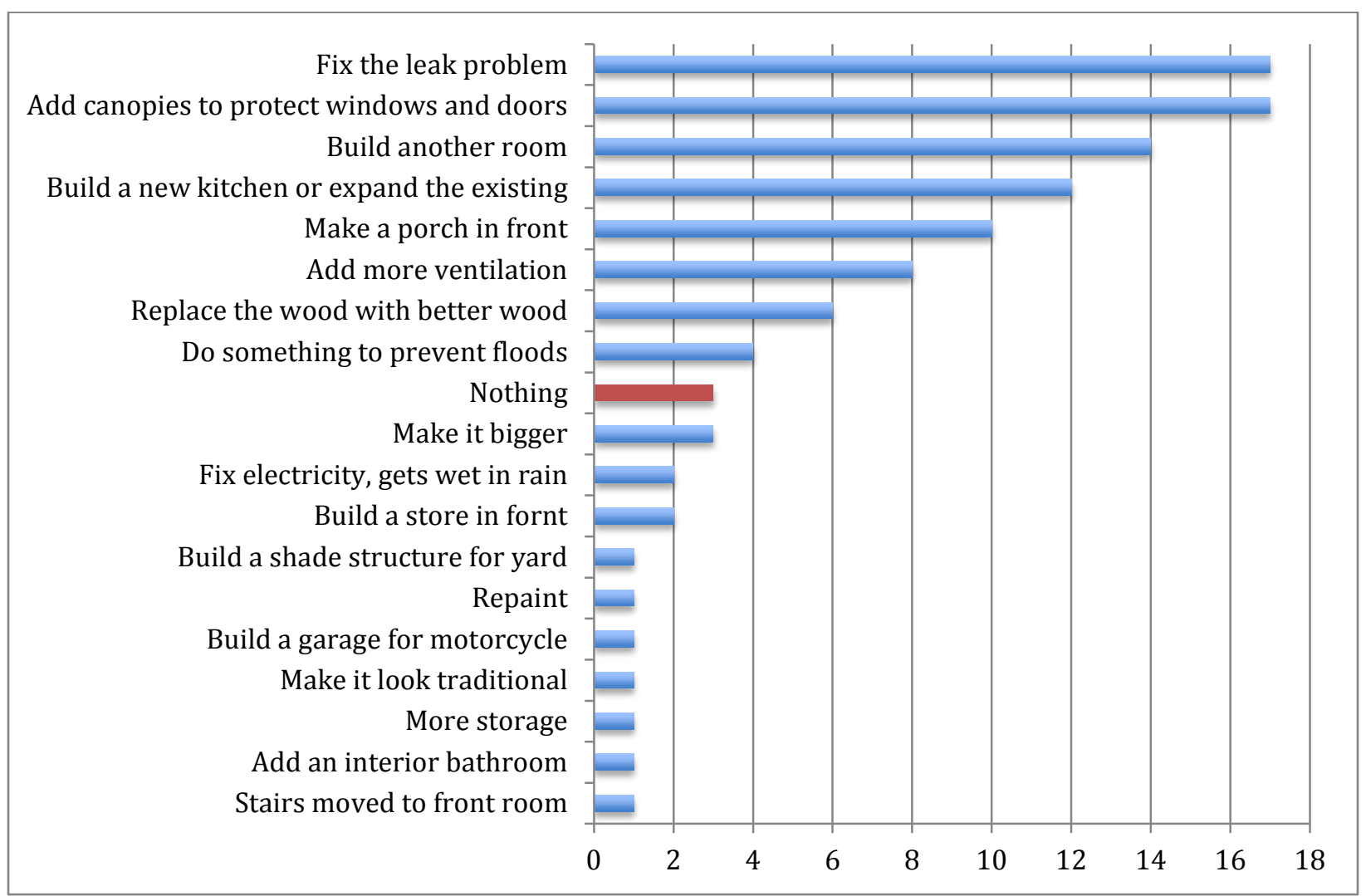

In addition to citing these problems, the residents are concerned that they do not know how to make necessary repairs to the buildings. The technology transfer process included equipment and training for initial construction, but there was no ongoing support offered to the community. In interviews with Mr. Haws it was indicated that at one point he traveled back to the village to construct some canopies, but no teaching or training of local residents occurred. Some home occupants have made attempts to expand or otherwise change their homes using traditional materials and methods in the typical self-help style of construction. It is unclear whether or not residents will be able to continue finding cost-effective solutions for all the listed concerns. 


\subsubsection{Tourism}

The creation of an isolated tourism economy is another unexpected outcome. Interviews with Rudi have indicated that periodically tour buses will drive to the village as part of other excursions, and visitors will roam the streets and photograph parts of New Ngelepen and its residents. During the field study the researcher observed a small plot of land that had been recently cleared in the sugar cane field bordering New Ngelepen. A large pile of rocks had been unloaded and will provide the foundation for a welcome center being constructed by the regional government. Most of the community is supportive of tourism, and the government is active in its promotion.

Also observed during the filed work was a visit to the village by two university students who had come in the middle of one morning to sight-see at the dome community. They stayed a short time and purchased a few items at one of the many home/shops. The most direct effect tourism brings to villagers is the opportunity to sell products to visitors. Packaged foodstuffs (home-made and commercially produced), bottled drinks, and dome paraphernalia are the main products offered. Some of the dome-branded items witnessed by the researcher were clothing, figurines, and printed pictures. Signage explaining the earthquake, the domes, and how the development came to this area has also been posted by representatives of the community.

Five of the village homeowners indicated that there should be more welcoming behavior of residents toward tourists. One respondent in particular shared the following "Some residents go inside and shut their doors when tourists arrive. But tourists are an income source and villagers should be kind to them.” Another resident offered a counter opinion, saying that the local informal leadership should relax the community rules and not focus the village toward tourism. 


\subsubsection{Expanded Marketplace}

Related to the aspect of tourism has been the development of a more significant market economy. Residents who are accustomed to subsistence living have found that selling goods to tourists, other dome community members, and even members of surrounding communities has been a good way to earn additional income. One woman interviewed explained, "I can make money here with my store...Before I moved to the dome I didn’t have a savings account. Now I built a store and am selling outside my home.” It was observed during the field study that there were seven homes openly displaying some sort of store-front appearance. There were several other households that were known to locals as also having goods to sell. Speaking of access to stores, seven of the New Ngelepen residents explained that the most significant difference between New Ngelepen and other communities is, "It is easier to find things.”

As indicated in four of the resident interviews, and two of the neighboring community interviews, those living in the new community must now purchase their vegetables. The plot size of each home is much smaller in comparison to residents’ pre-earthquake lots. This significantly reduces the amount of food that can be grown on their own land, increasing the need for households to purchase vegetables and herbs (critical food needs) from other sources. However, rice remains the staple food, with Indonesian diets incorporating rice in almost every meal. So increased vegetable purchases may be a financial burden to some degree, it may not be overly taxing to households.

\subsubsection{Community Economic Position}

New Ngelepen interview participants and participants from the neighboring communities, often made reference to the economic situation of the new dome village . It is interesting that 34 percent of the village residents claimed that their economic position has improved since moving 
into the dome village, and only 10 percent claimed that it had gone worsened. This is consistent with the neighboring communities’ perceptions. The most common response from neighbors when asked how they viewed the New Ngelepen residents was that they had imporved their economic position. It appears that the new technology implemented in New Ngelepen has produced positive unintended economic consequences through tourism and an increased market economy. However, it also appears that unfulfilled technology transfer expectations may have produced some negative consequences as owners seek to improve and enlarge their homes.

\subsection{Other Unintended Consequences}

There were a number of interesting observations pertaining to potential unintended consequences which did not have specific socio-economic implications in this study but may be significant later. Three categories were of particular interest to residents as indicated by interviews and research observations. The first was water and flooding in the lower section of the village. The second was the current lease status of land where the village was built. The third are functional components of the dome structures themselves.

\subsubsection{Flooding at Blocks $\mathrm{E}$ and $\mathrm{F}$}

Mr. Haws explained that the canal bordering the Western side of the village was built up with rocks and mortar to control the direction of the water. Early reports indicated that preliminary questions were asked prior to development in order to understand the potential of flooding. However, according to residents living in blocks E and F, during the rainy season the water backs up and floods the lower portion of the community usually once each year bringing as much as one-half meter of water into some of the lower houses. The drainage system of the community itself has been a problem, as homes have been built with insufficient elevation, allowing water to enter some homes in the upper blocks. This is a problem that owners are 
unsure how to fix and could be quite costly to remedy. A host of ditches and swales were constructed to divert water, they and offer some protection. Mr. Haws explained that this was not part of the original plan, but during construction it was obvious that water was going to be a bigger problem than anyone initially realized. Owners today cope with the flooding, but many of the interviews produced comments about water entering the domes and future plans to construct more ditches and water diverters.

\subsubsection{Land Lease Status}

The occupants inside the village are grateful for assistance, and all but a handful of residents have been there since the village was constructed. However, another finding emerged, a fear that the government would take their homes. Rudi explained the government assistance that virtually all persons in central Java received whose homes were destroyed by the earthquake. Approximately $\$ 1,500$ (US) in cash was given to the victims for rebuilding. The government estimated that homeowners could do their own labor, reclaim much of the brick materials from their collapsed homes, and then use the $\$ 1,500$ to purchase other new materials. Residents of New Ngelepen were technically not supposed to receive any money for their damaged homes and instead they would receive a new dome house. It was later learned that some dome recipients also received government aid money to repair their old homes.

The major issue was the legal status of the land itself. Domes for the World, according to the first reports, was to receive ownership of the land, which would eventually be transferred to the residents. During the field research it was learned, from informal interviews with the local government, that the land could not and was never to be given away. The government would be willing to sell the land to the villagers for a large sum, but the price is well beyond the financial capacity of the village. The government charges an annual lease payment for each structure. 
The lease payment is relatively small, currently $\$ 18 .^{00}$ (US) per year, but the fact they did not have title to their land created feelings of insecurity for the dome occupants, since most of the island of Java is privately owned and legal title is common even for the rural poor. Despite this insecurity, many residents have made improvements to the domes and live as though they will be there for a long time. The government supposedly has assured the people there will not be any forced evictions or changes in the village operation as long as the token yearly lease payments are made; however mistrust of the government is common in Indonesia.

\subsubsection{Functional Performance of Domes}

As mentioned previously, there are a number of problems related to the domes' functions that were not anticipated by the developers. While these problems illustrate economic consequences, they also are a functional concern, which was not anticipated. Primarily the concerns result from the design of the domes. According to the residents, insufficient ventilation creates too much heat inside the homes. The researcher verified this during the field study. The exterior cracking of plaster layers is an aesthetic consequence noted by many of the respondents from the community. The researcher noticed that small hairline cracks provide a place for moisture to accumulate, and in the worst cases, organics grow in the cracks making them seem larger and more unsightly. Poor quality of wood for windows and doors has created a leaking issue reported by most of the residents interviewed. Better louver design, specifications for higher-grade products for doors and windows, and/or integrated canopies on the domes' exteriors may have prevented the leak problems.

These functional outcomes, the land lease situation, and the periodic flood events are additional examples of negative consequences. Regardless of why these issues developed in the project, or even what the remedy is, they are unintended consequences of the development. It is 
not possible to know the full extent of these effects in the development presently, but it seems certain that they will have a persistent effect on residents. 


\section{CONCLUSIONS AND RECOMMENDATIONS}

\subsection{Answering the Question}

What are the unintended social and economic consequences resulting from the implementation of new technologies introduced by a foreign NGO in the construction of the planned community New Ngelepen, Indonesia?

The use of the inductive ethnographic case study allowed the researcher to pick an instance of development in the built environment and study it from multiple angles. Collecting the data generated during construction (in-depth interviews with the development agency’s personnel and archival records) described the intended outcomes and context of the development project. Data gathered four years after construction (field study observations, interviews with villagers inside and outside the community) yielded conclusions regarding the social and economic status of the community and its residents individually.

The analysis indicated that the planned community concept and the Monolithic EcoShell ${ }^{\mathrm{TM}}$ were the primary new technologies introduced. Further data analysis delivered the following general conclusions to the research question.

- The planned community model generated more social interaction between village members.

- The planned community model implemented was preferred over the previous rural lifestyle, by the village residents. 
- The planned community model may also be preferred over current lifestyles, by those households residing in the surrounding rural communities.

- Members of the planned community were more unified than members of other neighboring communities.

- Residents of New Ngelepen were progressing (in terms of social and economic development) faster than members of surrounding communities, and local governments were more inclined to assist the new community in development initiatives than surrounding communities.

- The transfer of technology intended by Domes for the World was not fully accomplished and has left a knowledge void of "proper" construction practice in replicating and repairing the dome structures; this is a concern to residents. This consequence is likely to become a more significant economic consequence for the residents in the future.

- A tourism economy has been established as a result of the unique dome shape of the buildings, and the high concentration of the structures in the planned community.

- A subsistence economy has shifted, in some degree, to a market economy for the village residents.

- The community's economic/financial position has been improved as a result of the new dome community.

- There are a number of functional unintended consequences that are specific to the dome structures and village as a whole. They were unaddressed as having no direct social or economic consequence, but may be interesting. 


\subsection{Surprising Conclusions}

After coding, tabulating, and analyzing the data, it is interesting to note that there were fewer negative unintended consequences than the researcher expected. In the development arena it seems that most studies report negative unintended consequences. Indeed there were some negative findings in this research project, but the majority of the social and economic unintended consequences were positive. The single conclusion from this research is that the net change in the socio-economic position for the community is a positive.

When the village of New Ngelepen is discussed, the domes are the prominent feature. Individuals inside and outside of the village refer to the domes as the defining characteristic of the community. However, 97 percent of the New Ngelepen residents felt that the domes fit within the rural central Javanese culture. Additionally, 100 percent of the interview participants in the surrounding area also said the dome structures fit the culture. Instead of defining their culture by the built environment, the people interviewed seemed to define their culture by the activities each person participated in. It was expected that the unique shape of the structures, the predominant physical feature of New Ngelepen, would have caused the predominant unintended socio-economic consequences. Perhaps the cultural acceptance of the structures negated this impact, regardless, the planned community concept clearly caused the greatest unexpected outcomes found in this study.

\subsection{The Problem of Doing Good}

Development is typically practiced by agencies and individuals who wish to "do good," and often their default method of doing good is some iteration of their current competencies and technologies. Domes for the World builds dome structures, in large part, because founders and participants have vast experience with this construction method/technology. Another example is 
USSynthetic, $^{8}$ which specializes in high-tech engineering and manufacturing. The director of corporate social responsibility for USSynthetic has changes his title to "Director of Engineering Good”, representing USSynthetic’s focus to take their core competency (engineering optimization) and addressing development needs like coconut oil processing in Kenya through reengineering of traditional equipment and processes.

New and innovative approaches to addressing development issues are helpful, perhaps even critical, but they fit within a set of steps required for sound development practice. The whole set must be initiated together for successful results. The steps are:

1. Determining what needs to satisfy (using a needs based or asset based approach for analysis).

2. Understanding the geographic area and culture where an action will take place.

3. Understanding how a development need fits within the local/regional/federal government and the international development community’s policy agendas.

4. Matching needs with appropriate action and appropriate technology.

5. Planning the specific development initiative.

6. Implementing the initiative.

Too often a motivated development group determines a need (step one) and then attempts to plan a solution and/or initiative to address the need (step five). This unsatisfied contextual analysis and appropriate solution finding can undermine the agency's successes, and can even cause an agency to do more harm than good. This pattern is an ongoing problem found in all sectors of the development arena.

\footnotetext{
${ }^{8}$ USSynthetic is a Utah-based company that designs and manufactures diamond bit drill heads for wells. They have initiated the creation of Non Governmental Organizations such as: Yehu Microfinance, Coast Coconut Farms, and the Pope Foundation.
} 
It is important to make clear that the motivation to help and do well is necessary for an individual's or agency's sustained involvement in development. Such commitment can lead to innovative thinking, and successfully bring new ideas/technologies into the field that have never been considered. New agencies often form around strong motivation and desire to do well. The root of the problem is these new agencies in the start-up phase often have no training to offset their lack of experience. A learn-by-doing approach is an effective teacher to the agency, but it can leave in its wake failed objectives and negative unintended consequences in first projects. For any project or program there will always be unexpected outcomes. However, experienced and/or trained organizations that follow all the steps of the practical development process will likely find they have fewer unanticipated negative results. In this case study, Domes for the World would be classified as a semi-trained agency, and seems to have been somewhat fortuitous in the largely positive unanticipated consequences. Additional studies to measure the appropriateness of intended objectives and success in achieving those objectives, coupled with the results of this study, would provide a more complete assessment of the overall success in the development project.

\subsection{Adaptability}

An answer to the question of why the new technologies in New Ngelepen were accepted so easily is the idea of cultural adaptability. Throughout the study there were a number of instances where the local people showed a tremendous ability to adapt to new ideas, or "make do" with what they had. It was evidently part of their culture to adapt to change. The following two examples of the grubbing hoe, and typical road construction illustrate the point.

The grubbing hoe is traditionally a farming tool, and the most common implement found in Indonesian homes, but was also used to mix concrete for construction (as well as screening sand, 
and preparing building pads for construction). The concrete was mixed in a pile of sand on the ground, meaning there was not always an equal proportioning of sand, cement, and water. In fact, very little cement was actually used in the mix, resulting in a low strength concrete mix. However, the important point is that the local people use what they have. They use a grubbing hoe in their fields (which is where they spend much of their time); then they use the same implement to mix the concrete. The hoe is not a tool perfectly suited to mix concrete, but it is familiar to the Indonesians and accomplishes the required task (see Figure 7).

In the next example, a traditional method for road building in the developed world has been adapted with less polished or complex tools. It is evident that basic principles of road building applied. Start with a solid base of rock; overlay with gravel; compact a finish grade of sand; finally apply a tar-based topcoat. The rocks in the base are unloaded and placed by hand, rather than using mechanical equipment such as a dump truck and front-end loader. An old model compactor runs over the gravel and sand levels (with no compaction testing), and then the hot tar is placed using a metal bucket with drain holes rather than automatic sprayers. To heat the tar, the workers use wood fueled fires under old 55-gallon drums (see Figure 8). 


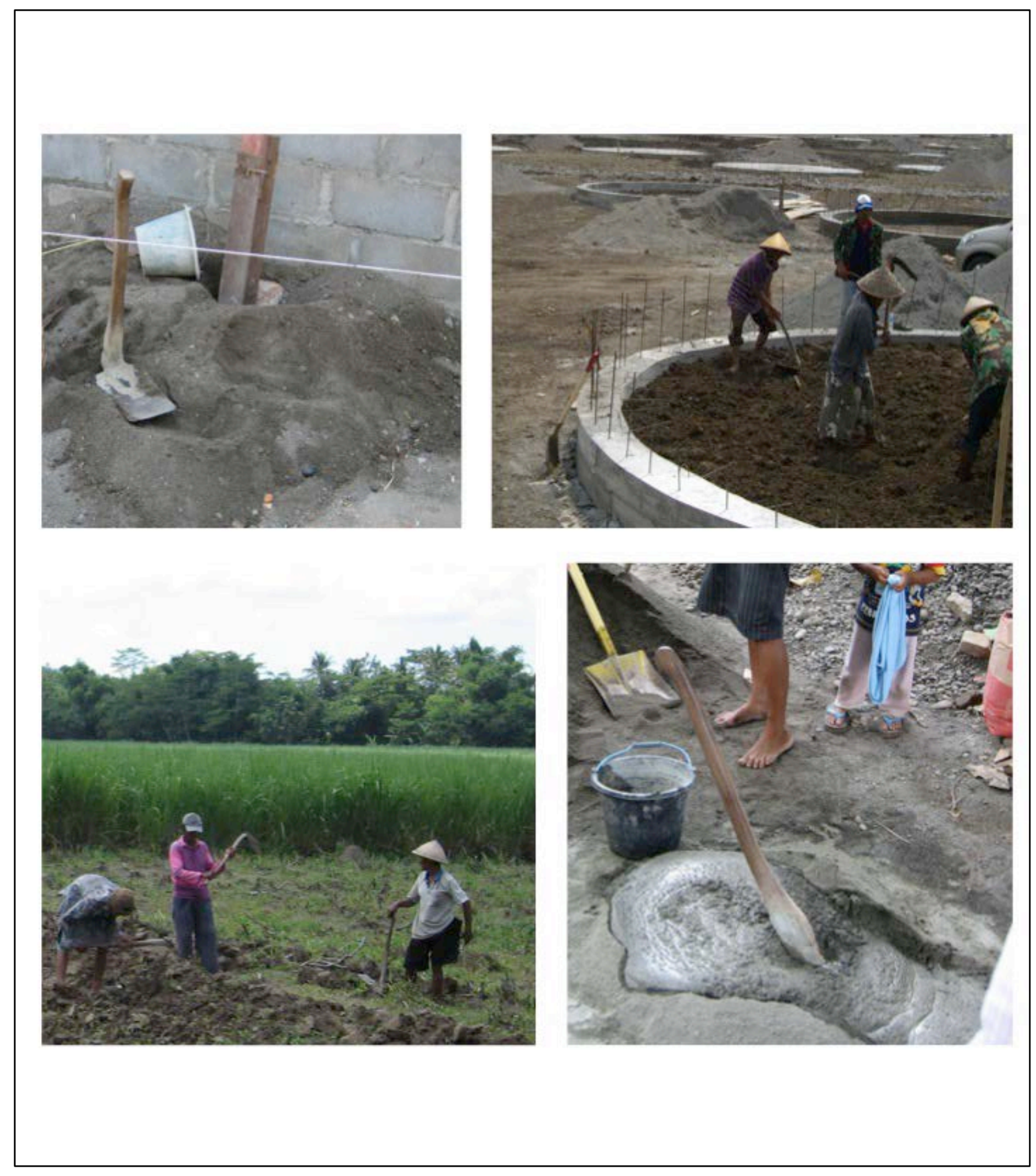

Figure 7: Indonesian Grubbing Hoe 


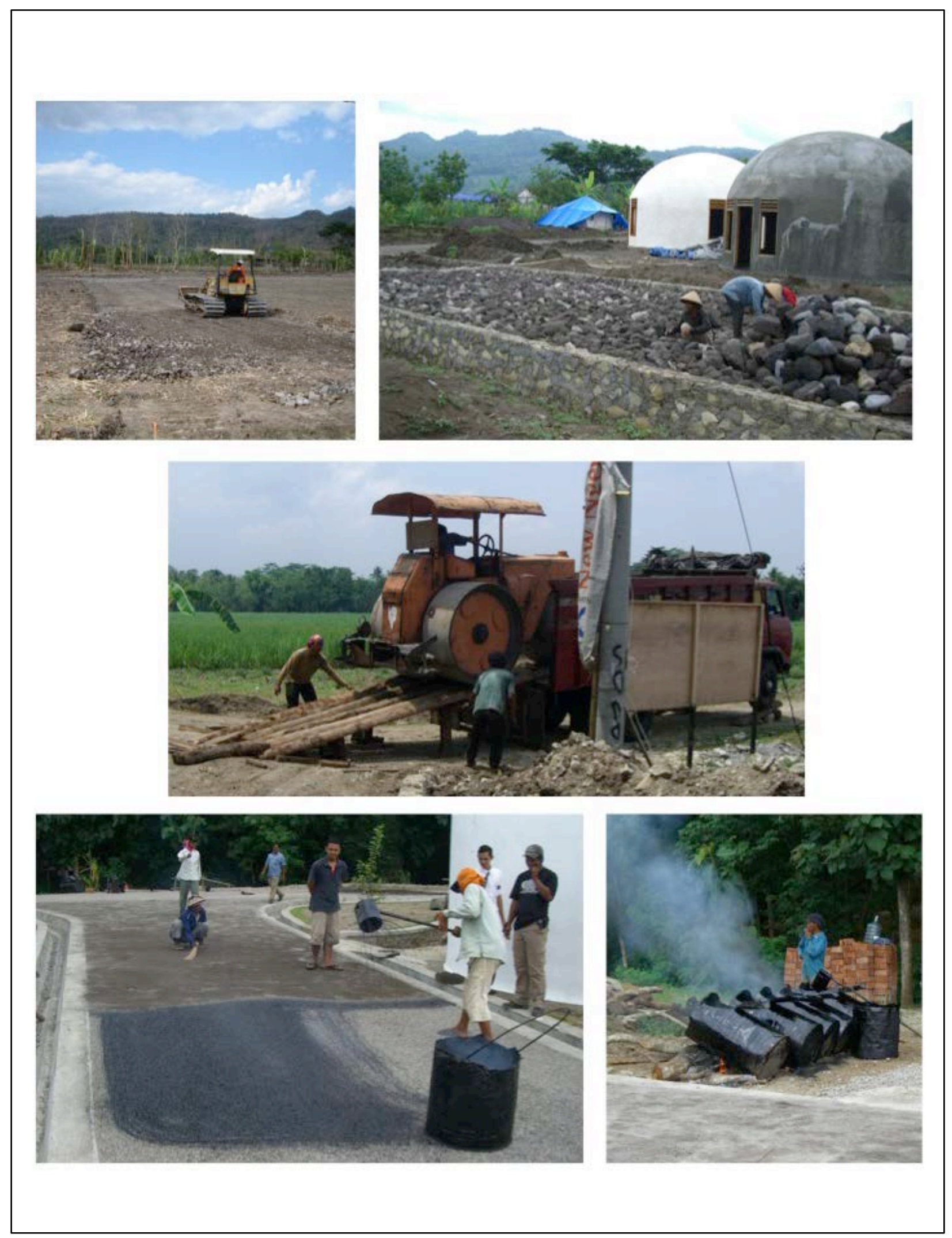

Figure 8: Traditional Road Building in Central Java 


\subsection{Application}

Prior to beginning this research project, the author expected to find in the concluding results of the study a list of application elements for development practice and dome construction methods ready for immediate use. This is likely due to his professional background in construction and monolithic dome project development, as enterprises traditionally succeed by solution finding and application of practical information. It was further expected, that the introduction of the dome-shaped structures would be the cause of the major unintended consequences identified, and that most would be negative. It has already been stated that most of the unintended consequences discovered in this study were positive, and they resulted from the planned community model, not the dome-shaped structures. It is also concluded that there is little in the way of application "keys” for development practice that can be taken from this study.

Some of the data collected may give insight to Domes for the World in terms of lessons learned, and in fact may offer insight for improved design and construction. However, as the author quickly realized in the review of related literature, this research question addresses an international development topic in its infancy. It is clearly an issue beginning the theorybuilding stage. Theory-testing and the derivation of practical application is at some point in the future.

\subsection{Future Research}

Additional research is clearly needed for this emerging discussion. For development practitioners, the most important topic to watch might be the idea of planned communities and their potential to foster progress in the developing world. As this study was introductory, the researcher is recommending the following areas for additional inductive study: 
- Observing cases where planned communities were introduced using construction technologies native to a locale.

- Observing cases where planned communities were introduced using other new construction technologies (specifically structure types, different from monolithic concrete domes) in addition to planned communities.

- Replicating this study in other geographic regions of the developing world These studies would aid in learning if and where planned communities improve the social and economic situations of rural residents in developing parts of the world, irrespective of geographic factors (climate, resources, etc.), culture, or other construction technologies implemented. Pursuing these research objectives will help to form testable hypotheses.

One tentative hypothesis regarding shelter types may be: when construction technologies fit traditional shelter parameters, then shape, method, and composition of a structure is much less a factor in altering the social and economic position of residents. Another tentative hypothesis regarding planned communities may be: planned communities produce positive changes in the social and economic positions of rural residents. Further qualitative study would surely give rise quantitative research opportunities. It is expected that additional research and the contributions of many others will provide significant improvements to the practice of introducing new technologies to the built environments of the developing world. The author is optimistic that such improvements would have the potential to offer significant positive influences for individuals, families, communities, and nations of the developing world. 


\section{REFERENCES}

Abbott, P.G. Technology Transfer in the Construction Industry: Infrastructure and Industrial Development Eiu, the Economist Intelligence Unit. Special Report, 223. London: Economist Publ., 1985.

Adams, W.M. Green Development: Enviornment and Sustainability in the Thrid World. 2nd ed. London: Routledge, 2001.

Antle, J.M., and G. Heidebrink. "Environment and Development: Theory and International Evidence." Economic Development and Cultural Change 43, no. 3 (1995): 603-625.

Arman, M., J. Zuo, L. Wilson, G. Zillante, and S. Pullen. "Challenges of Responding to Sustainability with Implications for Affordable Housing." Ecological Economics 68, no. 12 (2009): 3034-3041.

Asadi-Lari, M., A.A. Farshad, S.E. Assaei, M.R.V. Mahdavi, M.E. Akbari, A. Ameri, Z. Salimi, and D. Gray. "Applying a Basic Development Needs Approach for Sustainable and Integrated Community Development in Less-Developed Areas: Report of Ongoing Iranian Experience." Public Health 119, no. 6 (2005): 474-482.

Beattie, N.M., Campbell; Brigitte, Yildirim. "Incremental Housing: Solutions to Meet the Global Urban Housing Challenge." In UN World Urban Forum. Brazil: Global University Consortium - SIGUS-MIT, 2010.

Brandon, P., and P. Lombardi. Evaluating Sustainable Development in the Built Enviornment. West Sussex: Wiley-Blackwell, 2005.

Bredenoord, J., and P. van Lindert. "Pro-Poor Housing Policies: Rethinking the Potential of Assisted Self-Help Housing." Habitat International 34, no. 3 (2010): 278-287.

Brutland, G.H., and M. Khalid. Our Common Future, Edited by Development World Commission on Environment and. Oxford ; New York: Oxford ; New York : Oxford University Press, 1987.

Brzev, S. "Non-Ductile Rc Frames and Alternative Improved Construction Technologies." Beijing: The 14th World Conference on Earthquake Engineering, 2008.

Chan, R.C.K., Y.M. Yao, and S.X.B. Zhao. "Self-Help Housing Strategy for Temporary Population in Guangzhou, China." Habitat International 27, no. 1 (2003): 19-35.

Collins, A.E. Disaster and Development. New York: Routledge, 2009. 
Commission, I.H.R., "Frequently Asked Questions", Interim Haiti Recovery Commission http://www.cirh.ht/sites/ihrc/en/About Us/Pages/Frequently Asked Questions.aspx (accessed May 23 2011).

Costanza, R., B. Fisher, S. Ali, C. Beer, L. Bond, R. Boumans, N.L. Danigelis, J. Dickinson, C. Elliott, J. Farley, D.E. Gayer, L.M. Glenn, T. Hudspeth, D. Mahoney, L. McCahill, B. McIntosh, B. Reed, S.A.T. Rizvi, D.M. Rizzo, T. Simpatico, and R. Snapp. "Quality of Life: An Approach Integrating Opportunities, Human Needs, and Subjective WellBeing." Ecological Economics 61, no. 2-3 (2007): 267-276.

Creswell, J.W. Qualitative Inquiry and Research Design: Choosing among Five Approaches [with Cd-Rom]. Second Edition, 2006.

Crook, R.M., James. "Democratic Decentralization." In OED Working Paper Series. Washington, D.C.: The World Bank Group, 2000.

Dasgupta, P., and K.G. Maler. "The Enviornment and Emerging Development Issues." 28-42. London: London School of Economics, 1990.

Davidson, C.H., C. Johnson, G. Lizarralde, N. Dikmen, and A. Sliwinski. "Truths and Myths About Community Participation in Post-Disaster Housing Projects." Habitat International 31, no. 1 (2007): 100-115.

Degnbol-Martinussen, J. Aid: Understanding International Development Cooperation: John Degnbol-Martinussen and Poul Engberg-Pedersen ; Translated by Marie Bille, Edited by Poul Engberg-Pedersen: London; New York; Copenhagen; New York: Zed Books: Mellemfolkeligt Samvirke, Danish Association for International Cooperation: Distributed in the USA exclusively by Palgrave, 2003.

Deng, F. "Post-Disaster Reconfiguration of Property Rights in a Transition Economy." PostCommunist Economies 22, no. 2 (2010): 193-206.

DFTW. "Feasibility Study; Yogyakarta." Domes for the World, 2006.

Ellis, F., and S. Biggs. "Evolving Themes in Rural Development 1950s-2000s." Development Policy Review 19, no. 4 (2001): 437-448.

Ellis, S., and S. Barakat. "From Relief to Development: The Long-Term Effects of 'Temporary' Accommodation on Refugees and Displaced Persons in the Republic of Croatia." Disasters 20, no. 2 (1996): 111-124.

Ennis, G., and D. West. "Exploring the Potential of Social Network Analysis in Asset-Based Community Development Practice and Research." Australian Social Work 63, no. 4 (2010): 404-417. 
Fisher, K., J. Geenen, M. Jurcevic, K. McClintock, and G. Davis. "Applying Asset-Based Community Development as a Strategy for Csr: A Canadian Perspective on a Win-Win for Stakeholders and Smes." Business Ethics-a European Review 18, no. 1 (2009): 66-82.

Ganesan, S., and J. Kelsey. "Technology Transfer: International Collaboration in Sri Lanka." Construction Management \& Economics 24, no. 7 (2006): 743-753.

Gilbert, A. "Housing in Third World Cities: The Critical Issues." Geography 85 (2000): 145-155.

Glenn, J.M., R.P. Labossiere, and J.M. Wolfe. "Squatter Regularization - Problems and Prospects - a Case-Study from Trinidad." Third World Planning Review 15, no. 3 (1993): 249-262.

Haiti. "Action Plan for National Recovery and Development of Haiti." In Immediate key initiatives for the future. Port-au Prince, Haiti: Government of the Republic of Haiti, 2010.

. "Haiti Earthquake Pdna: Assessment of Damage, Losses, General and Sectoral Needs." In Annex to the Action Plan for National Recovery and Development of Haiti: Government of the Republic of Haiti, 2010.

Hall, L. Economic Development and Cultural Change 23, no. 4 (1975): 769-771.

Hammond, A.L., and C.K. Prahalad. "Selling to the Poor." Foreign Policy, no. 142 (2004): 3037.

Hodgkin, D. "Interview." edited by Andrew South, 2011.

"Java", Encyclopedia Britannica http://www.britannica.com/EBchecked/topic/301673/Java (accessed May 2011).

Karnani, A. "The Mirage of Marketing to the Bottom of the Pyramid: How the Private Sector Can Help Alleviate Poverty." CALIFORNIA MANAGEMENT REVIEW 49, no. 4 (2007): 90-+.

Kretzman, J.P., and J.L. McKnight. Building Communities for the inside Out: A Path toward Finding and Mobilizing a Community's Assets. Chicago: ACTA Publications, 1993.

Levinsohn, J., M.S. McMillan, and National Bureau of Economic Research. "Does Food Aid Harm the Poor? Household Evidence from Ethiopia." NBER working paper series working paper 11048 (2005).

Littig, B., and E. Griessler. "Social Sustainability: A Catchword between Political Pragmatism and Social Theory." International Journal of Sustainable Development 8, no. 1 (2005): 65-79. 
Lizarralde, G., and M. Massyn. "Unexpected Negative Outcomes of Community Participation in Low-Cost Housing Projects in South Africa." Habitat International 32, no. 1 (2008): 114.

Lofland, J. Analyzing Social Settings: A Guide to Qualitative Observation and Analysis: John Lofland, Lyn H. Lofland, Edited by Lyn H. Lofland: Belmont, Calif.: Wadsworth Pub. Co., 1984.

MacRae, G., and D. Hodgkin. "Half Full or Half Empty? Shelter after the Jogjakarta Earthquake." Disasters 35, no. 1 (2011): 243-267.

Mandelker, D.R. Designing Planned Communities. New York: iUniverse, Inc., 2010.

Mansuir, G., and V. Rao. "Community Based (and Driven) Development: A Critical Review." Washinton D.C.: The World Bank, Development Research Group, 2003.

Maslow, A. Motivation and Personality. 3rd ed. New York: Harper and Row, 1987.

Mathie, A., and G. Cunningham. "Who Is Driving Development? Reflections on the Transformative Potential of Asset-Based Community Development." St. Francis Xavier University, Antigonish, NS, Canada, 2003.

Merton, R.K. "The Unanticipated Consequences of Purposive Social Action." American Sociological Review 1, no. 6 (1936): 894-904.

Mitlin, D., and D. Satterthwaite. "Strategies for Grassroots Control of International Aid." Environment and Urbanization 19, no. 2 (2007): 483-500.

Moavenzadeh, F. "Construction Industry in Developing Countries." World Development 6, no. 1 (1978): 97-116.

Nientied, P., S.B. Mhenni, and J. de Wit. "Community Participation in Low-Income Housing Policies: Potential or Paradox." Community Development Journal 25, no. 1 (1990): $42-$ 55.

Ofori, G. "Construction Industry Development: Role of Technology Transfer." Construction Management \& Economics 12, no. 5 (1994): 379.

. "Practice of Construction Industry Development at the Crossroads." Habitat International 18, no. 2 (1994): 41-56.

Oyugi, M.O. "Towards Sustainable Shelter Provision in Africa: Kenyan Experience." Discovery and Innovation 17, no. 1-2 (2005): 27-36.

Pearce, D., E. Barbier, and A. Markandya. Sustainable Development: Economics and the Enviornment in the Third World. London: Edward Elgar Publishing Limited, 1990. 
Pelto, P.J. The Snowmobile Revolution; Technology and Social Change in the Arctic [by] Pertti J. Pelto. Menlo Park, Calif.: Menlo Park, Calif. : Cummings Pub. Co., 1973.

Polak, P. Out of Poverty. San Francisco: Berrett-Koehler Publishers, Inc., 2008.

Porter, M.E., and M.R. Kramer. "The Competitive Advantage of Corporate Philanthropy." Harvard Buiness Review, no. R0212D (2002).

Potter, R.B. The City in the Developing World. Essex: Addison Wesley Logman Limited, 1998.

Prahalad, C.K. The Fortune at the Bottom of the Pyramid; Eradicating Poverty through Profits. Upper Saddle River: Wharton School Publishing, 2010.

Reading, M. "Building Back Better Communities." In Request for Proposal on behalf of the Government of the Republic of Haiti. London: Malcom Reading Consultants, 2010.

, "New Housing Competition for Haiti", Malcom Reading Consultants Limited http://www.malcolmreading.co.uk/news/story/new_housing_competition_for_haiti/ (accessed May 23 2011).

Reardon, T., and S.A. Vosti. "Links between Rural Poverty and the Environment in Developing Countries: Asset Categories and Investment Poverty." World Development 23, no. 9 (1995): 1495-1506.

Rondinelli, D.A. "Housing the Urban Poor in Developing Countries." American Journal of Economics and Sociology 49, no. 2 (1990): 153-166.

Sabatier, P.A. "Top-Down and Bottom-up Approaches to Implementation Research: A Critical Analysis and Suggested Synthesis." Journal of Public Policy 6, no. 01 (1986): 21-48.

Silva, J.d. "Lessons from Aceh." In Key Considerations in Post-Disaster Reconstruction, 98. Warwickshire, UK: Practical Action Publishing Ltd, 2010.

South, D., "More About Monolithic's Ecoshell 1", Monolithic Dome Institute http://www.monolithic.com/stories/more-about-monolithic-s-ecoshell-1 (accessed May 2011).

Spradley, J.P. The Ethnographic Interview. New York: Holt, Rinehart, and Winston, 1979.

Stake, R.E. The Art of Case Study Research. Thousand Oaks: Thousand Oaks : Sage Publications, 1995.

Stiles, K. "International Support for Ngos in Bangladesh: Some Unintended Consequences." World Development 30, no. 5 (2002): 835-846. 
Strauss, A.L. Basics of Qualitative Research : Grounded Theory Procedures and Techniques, Edited by Juliet M. Corbin. Newbury Park, Calif.: Newbury Park, Calif. : Sage Publications, 1990.

UNDP. Human Development Report 2010. New York, 2010.

UNDP, UNESCO, UNFPA, UNICEF, and WHO. "The 20/20 Initiative: Achieving Universal Access to Basic Social Services for Sustainable Human Development." New York: UNICEF, 1994.

USGS, "Magnitude 7.0 - Haiti Region", U.S. Geological Survey, National Earthquake Information Center http://earthquake.usgs.gov/earthquakes/recenteqsww/Quakes/us2010rja6.php (accessed May 23 2011).

WB. Disease Control Priorities in Developing Countries. Washington: Washington : The World Bank, 2006.

Woolcock, M., and D. Narayan. "Social Capital: Implications for Development Theory, Research, and Policy." The World Bank Research Observer 15, no. 2 (2000): 225-249. 
APPENDICES 


\section{APPENDIX A}

\section{Participant Interview Invitation and Interviewer Instructions:}

Ask to speak with the mother or father of the home. Before entering the house, say:

Hi, my name is . I work for Domes for the World, who helped to develop this community. We are conducting interviews to help the organization improve its future development programs. We would like to ask some questions about your home and the community. The interview takes about 15-30 minutes to complete. Could we come inside for an interview?

Before beginning the interview, say:

Your answers to all questions in this interview will be completely confidential. The interview does not present any risks for you or your family, and does not provide any benefits. Your participation is completely voluntary; if you do not wish to answer a question then you are not obligated to respond.

\section{Suggestions:}

1.Be familiar and comfortable with the guidance questions in the interview

2. Conduct the interview in a comfortable place, where there is minimal distraction and noise.

3. When they do not immediately respond, do not suggest an answer.

4.Don't read the question in any other form than exactly as it appears.

5.Assure them of the confidentiality of their answers 


\section{APPENDIX B}

\section{Interview Guidance Questions for Dome Community Residents}

Basic Demographic Questions:

- How many people live in this home?

- How long have you lived in this home?

Interview Guidance Questions:

1.What do you like best about your home?

2.What do you like least about your home?

3.How is living in this community different than living in a traditional community?

4. What would you change about the community?

5.Do you feel this community fits your culture?

6. How do others (outside this community) view you, now that you live in this community?

7.What would you change about your home?

8. Would you prefer to live in a dome house or a traditional house?

9.If you could trade your dome house for a traditional house, would you do that?

10. If you had a choice between a 2-story dome house of this size (like the one you are in) or a 1-story dome house that does not have a second floor, but has the same amount of square footage, which would you prefer?

11. How has your economic status changed since the earthquake and moving into the dome community? Are you financially better off?

12. Has the quality of your life gone up or down since moving into the dome house? 


\section{APPENDIX C}

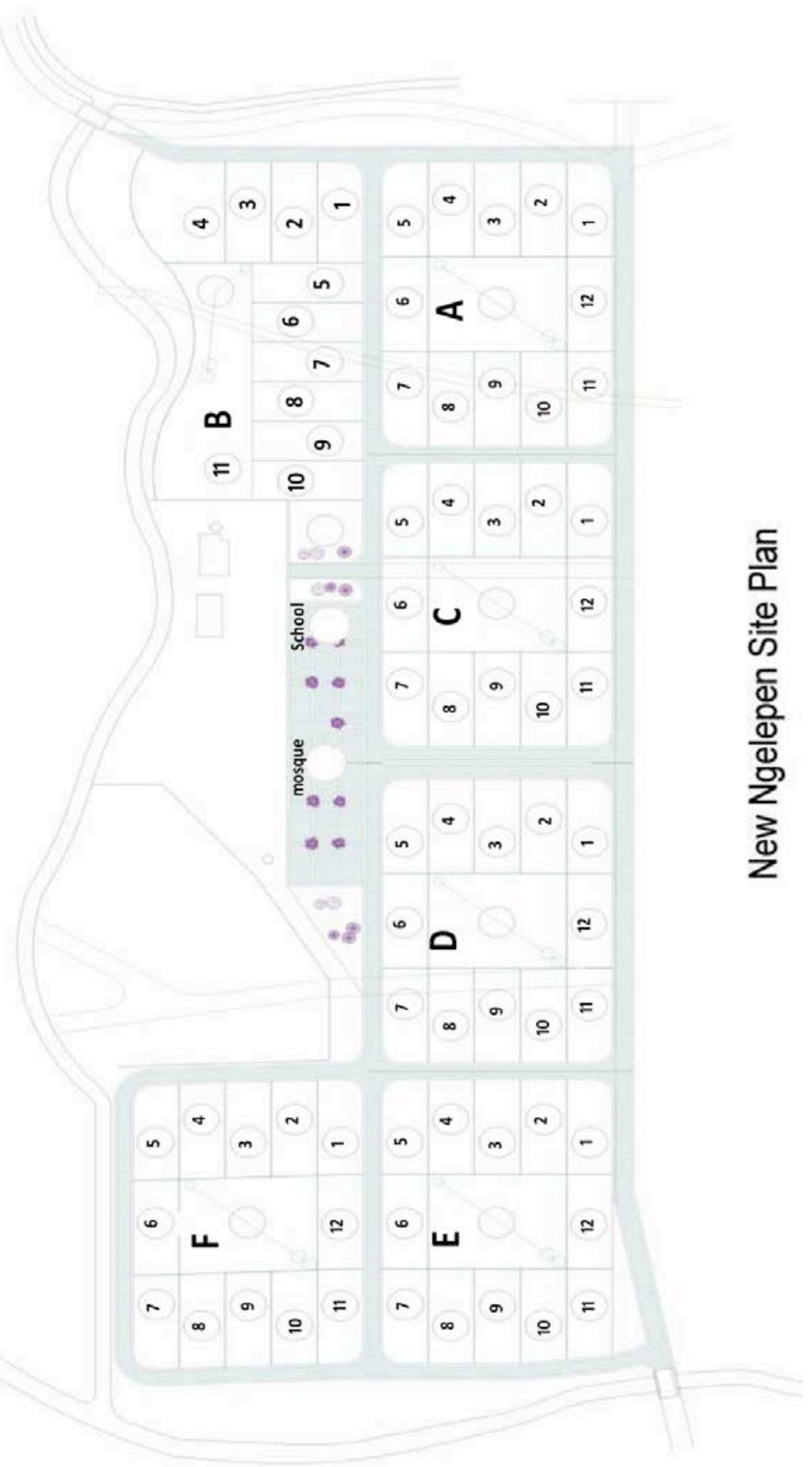




\section{APPENDIX D}

Ariel Photograph of Interviews Conducted in the Community Area

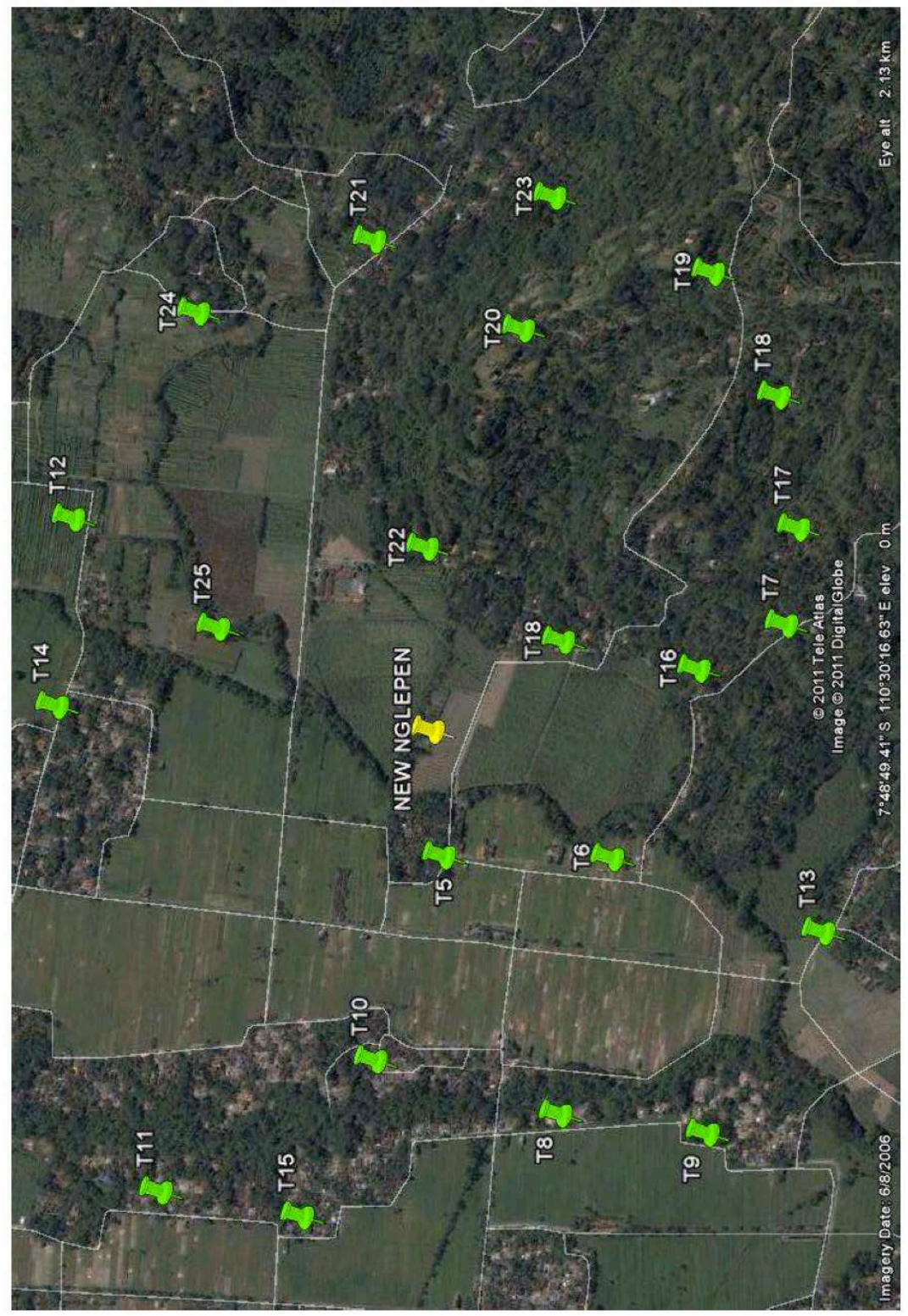




\section{APPENDIX E}

\section{Interview Guidance Questions for Residents of Surrounding Communities}

Basic Demographic Questions:

- How many people live in this home?

- How long have you lived in this home?

Interview Guidance Questions:

1.What do you like best about your home?

2. What do you like least about your home?

3. Do you think it is different living in a dome community?

4. What would you change about the community?

5.Do you think a dome community fits your culture?

6. How do you view those living in the dome community?

7.What would you change about your home?

8. Would you prefer to live in a dome house or a traditional house?

9. Would you trade your traditional house for a dome house? 


\section{APPENDIX F}

Tabulation of New Ngelepen Occupants

\begin{tabular}{|c|c|c|c|c|c|}
\hline Lot/Block & Father & Mother & Children & Other & TOTAL \\
\hline $\mathrm{A} 1$ & 1 & 1 & 1 & & 3 \\
\hline $\mathrm{A} 2$ & 1 & 1 & 2 & & 4 \\
\hline A3 & 1 & 1 & 2 & & 4 \\
\hline A4 & 1 & 1 & 1 & & 3 \\
\hline A5 & 1 & 1 & 1 & & 3 \\
\hline A6 & 1 & 1 & & & 2 \\
\hline A7 & 1 & 1 & 2 & & 4 \\
\hline A8 & 1 & 1 & 2 & & 4 \\
\hline A9 & 1 & 1 & & & 2 \\
\hline A10 & 1 & 1 & & & 2 \\
\hline A11 & 1 & 1 & & & 2 \\
\hline A12 & 1 & 1 & 2 & & 4 \\
\hline B1 & 1 & 1 & 1 & & 3 \\
\hline B2 & 1 & 1 & & & 2 \\
\hline B3 & 1 & 1 & 2 & & 4 \\
\hline B4 & 1 & 1 & 3 & & 5 \\
\hline B5 & & & & & 0 \\
\hline B6 & & 1 & & & 1 \\
\hline B7 & 1 & 1 & 2 & & 4 \\
\hline B8 & 1 & 1 & 1 & & 3 \\
\hline B9 & 1 & 1 & 2 & & 4 \\
\hline B10 & 1 & 1 & & & 2 \\
\hline B11 & 1 & 1 & 2 & & 4 \\
\hline $\mathrm{C} 1$ & 1 & & & & 1 \\
\hline $\mathrm{C} 2$ & 1 & 1 & 1 & & 3 \\
\hline C3 & 1 & 1 & 2 & & 4 \\
\hline $\mathrm{C4}$ & 1 & 1 & 2 & & 4 \\
\hline C5 & 1 & 1 & 2 & & 4 \\
\hline C6 & 1 & 1 & 1 & & 3 \\
\hline
\end{tabular}




\begin{tabular}{|c|c|c|c|c|c|}
\hline $\mathrm{C} 7$ & 1 & 1 & 2 & & 4 \\
\hline $\mathrm{C} 8$ & 1 & 1 & 1 & & 3 \\
\hline $\mathrm{C9}$ & 1 & 1 & 2 & & 4 \\
\hline C10 & 1 & 1 & 2 & & 4 \\
\hline C11 & & & & & 0 \\
\hline C12 & 1 & 1 & 1 & & 3 \\
\hline D1 & 1 & 1 & 1 & & 3 \\
\hline D2 & 1 & 1 & & & 2 \\
\hline D3 & 1 & 1 & 1 & & 3 \\
\hline D4 & & 1 & & & 1 \\
\hline D5 & 1 & 1 & & & 2 \\
\hline D6 & 1 & 1 & 1 & & 3 \\
\hline D7 & & & & & 0 \\
\hline D8 & 1 & 1 & 1 & & 3 \\
\hline D9 & 1 & 1 & 1 & & 3 \\
\hline D10 & 1 & 1 & 4 & 1 & 6 \\
\hline D11 & 2 & 2 & 1 & & 5 \\
\hline D12 & 1 & 1 & 3 & & 5 \\
\hline E1 & 1 & 1 & 1 & & 3 \\
\hline E2 & 1 & 1 & & & 2 \\
\hline E3 & 1 & 1 & 1 & & 3 \\
\hline E4 & 1 & 1 & 2 & & 4 \\
\hline E5 & 1 & 1 & & & 2 \\
\hline E6 & 1 & 1 & 2 & & 4 \\
\hline E7 & & & & & 0 \\
\hline E8 & & 1 & & & 1 \\
\hline E9 & 1 & 1 & 2 & & 4 \\
\hline E10 & 1 & 1 & 2 & 1 & 4 \\
\hline E11 & 1 & 1 & 1 & & 3 \\
\hline E12 & 1 & 1 & 2 & & 4 \\
\hline $\mathrm{F} 1$ & 1 & 1 & 2 & & 4 \\
\hline F2 & 1 & 1 & 1 & & 3 \\
\hline F3 & 1 & 1 & 3 & & 5 \\
\hline F4 & 1 & 1 & 1 & & 3 \\
\hline F5 & 1 & 1 & 1 & & 3 \\
\hline F6 & 2 & 2 & 2 & & 6 \\
\hline F7 & 1 & & & & 1 \\
\hline F8 & 0 & 0 & 0 & & 0 \\
\hline F9 & 1 & 1 & 2 & & 4 \\
\hline F10 & 1 & 1 & 2 & & 4 \\
\hline F11 & & 1 & & & 1 \\
\hline F12 & 1 & 1 & 2 & & 4 \\
\hline
\end{tabular}


Tabulation of Occupants from Households Surveyed in Surrounding Communities

\begin{tabular}{cccccc} 
Lot/Block & Father & Mother & Children & Other & TOTAL \\
\hline T1 & 1 & 1 & 2 & & 4 \\
T2 & 1 & 1 & 2 & 1 & 4 \\
T3 & 1 & 1 & 4 & & 6 \\
T4 & 1 & 1 & & & 2 \\
T5 & 1 & 1 & 1 & & 3 \\
T6 & 1 & 1 & 1 & & 3 \\
T7 & 1 & 1 & 1 & 1 & 3 \\
T8 & 1 & 1 & 2 & & 4 \\
T9 & 1 & 1 & 1 & & 3 \\
T10 & 1 & 1 & & & 2 \\
T11 & & 1 & 2 & & 3 \\
T12 & 1 & 1 & 2 & 1 & 4 \\
T13 & 1 & 1 & 1 & & 3 \\
T14 & 1 & 1 & 3 & & 5 \\
T15 & 1 & 1 & 2 & & 4 \\
T16 & 1 & 1 & 1 & & 3 \\
T17 & 1 & 1 & 2 & & 4 \\
T18 & 1 & 1 & & & 2 \\
T19 & 1 & 1 & 2 & & 4 \\
T20 & 1 & 1 & 2 & \\
T21 & 1 & 1 & 1 & \\
T22 & 1 & 1 & 3 & 3 \\
T23 & 1 & 1 & 2 & \\
T24 & 1 & 1 & 1 & & 4 \\
& & & & &
\end{tabular}

